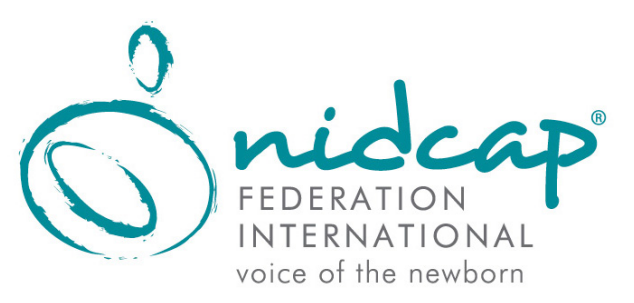

Developmental

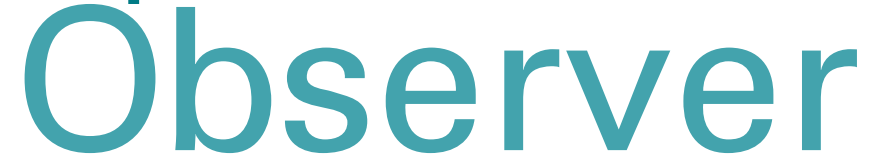

The Official Newsletter of the NIDCAP ${ }^{\circledR}$ Federation International

\section{NIDCAP Federation}

International (NFI)

Founded in 2001, the NFI is an international, non-profit membership organization. The NFI encourages highly attuned implementation of the Newborn Individualized Developmental Care and Assessment Program (NIDCAP) for all intensive, special care and newborn nurseries around the world. The NFI serves as the authoritative leader for research, development, and dissemination of NIDCAP, and for the certification of trainers, healthcare professionals, and nurseries in the NIDCAP approach.

"Rejoice with your family in the beautiful land of life."

Albert Einstein

\section{Table of Contents}

The Strength of NFI's Collective Experience 1

Editorial .... 2

Putting Beauty at the Heart of the Healing Process . .3

Family Voices. 5

Reflections on Infant Feeding 8

Global Perspective of Developmental Care - Cyprus

My NIDCAP Journey as an Interpreter

NIDCAP Training Centers Around the World 16

The Science Desk 18

Publications .21

Poet's Corner .25

NIDCAP on the Web 27

ISSN: 2689-2650 (online) DO 13:2 full issue DOI: 10.14434/do.v13i2.31223

\section{The Strength of the NFI's Collective Experience}

\section{Deborah Buehler, PhD}

President, NIDCAP Federation International DOI: 10.14434/do.v13i2.31301

$\mathrm{O}$ ne of my very early experiences as a NIDCAP Trainer took me to Falun, Sweden. While I was there, I shared NIDCAP's introductory lecture and guided a few introductory bedside observations. With that visit, the healthcare team learned about

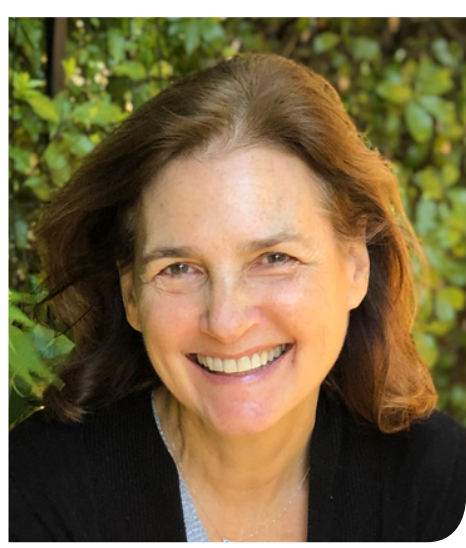

Deborah Buehler, PhD NIDCAP and a new group of NIDCAP trainees was launched. What I remember most about that trip was how much I learned. My understandings of what was and what could be possible within hospital care was completely expanded by the people I met and the care I observed. During one particular NIDCAP observation, I vividly remember a mother and her baby and the nurse caring for them. They were so beautifully attuned with one another that I was mesmerized. Over the several days I visited the nursery, I learned that aspects of medical and nursing care could be done in different ways than I had seen practiced in U.S. hospitals. During the breaks of my lecture, I remember a physical therapist leading the whole audience, of physicians, nurses and therapists, through joyful stretching breaks with children's songs, which included The Itsy-Bitsy Spider. It was evident these small, yet powerful moments of silliness were remarkable for the respect and cohesiveness of the whole healthcare team. I especially remember this NIDCAP training session, nearly 30 years ago, in part, because it was my first solo international trip which posed challenges on many levels for me. Perhaps being stretched in new ways created opportunities to be open to seeing and being shaped by my experiences. This moment in time captured my imagination and continues to inform my NIDCAP training and mentoring of trainees and health care professionals and their resolve to evolve their care to be ever more supportive.

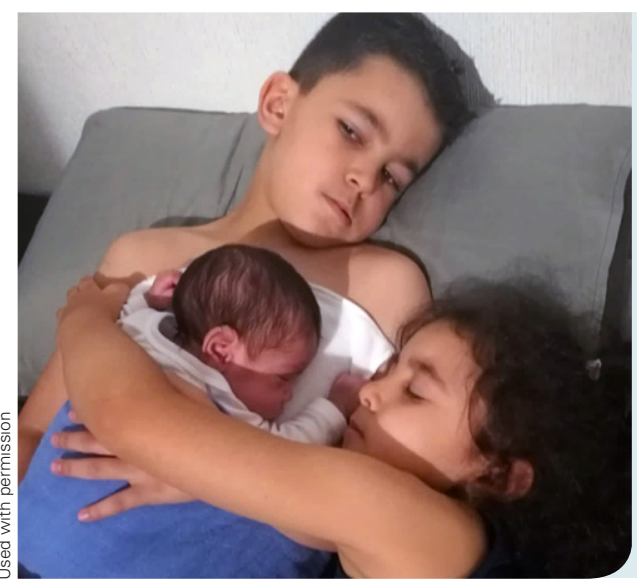

NIDCAP Care in the Moment

Family Strength

Collaboration and support for and from each infant's family is the core of NIDCAP. 
2020 is continually described as unprecedented (our world has never faced this scale of international pandemic before) and as creating a new normal (life is very quickly changing as we adapt around the world). Everything appears to be affected. This most certainly includes access to and the experience of hospitalizations and healthcare. Within newborn and infant intensive and special care nurseries, parents are being separated from their newborns and young infants because of hospital infection precautions. Healthcare professionals are tasked with providing medical care in the face of tremendous barriers, workloads and sacrifices. How do healthcare professionals, and the families they serve, understand and navigate all of this extraordinary adversity? One key to these understandings may be hearing and reflecting on the stories, the struggles and the triumphs, of everyone who is part of these systems of care. Brené Brown, PhD, LMSW, a research professor, wrote "maybe stories are just data with a soul." Families' and professionals' lived experiences, including ones of pain and suffering, may provide insight, inspiration and direction for healthcare's next steps. Much has been written on how hardship impacts individuals. For instance, Kaufman and Gregoire (2015) stated that "experiences of extreme adversity show us our own strength." (p. 146) Beyond survival, these authors optimistically described how individuals may also thrive with adversity. This capacity for resilience is a profound strength that offers stability and growth for individuals as well as for healthcare systems.

This unprecedented year is also creating challenges and a new normal for the NFI and NIDCAP efforts. NIDCAP Training
Centers and their Trainers are faced with how to educate and guide trainees and hospitals with in-person and travel restrictions. This comes at a time when individual and system-wide support is needed more than ever. How will the NFI navigate the short and long-term challenges ahead? To thrive as an organization in this rapidly changing world, the NFI must respond to the incredible realities faced by NIDCAP Trainers around the world. Examining difficulties, strengths and opportunities are crucial at this time. Drawing on the remarkable skill, passion and experience within our community, we must listen, question, discuss, reflect, learn and create with one another. Innovations for training, education and support may emerge as the NFI's members, its NIDCAP Trainers and supporters, continue to share their own experiences and perspectives with one another. Our global NFI community offers tremendous strength and wisdom to draw upon for stability and direction. Support for and from one another may lead to inspiration of creative possibilities to build future directions. The NFI, and its members, have a tremendous opportunity to rise up to meet this extremely difficult moment in time. How 2020 captures our collective hearts and imaginations and informs our next steps will ensure that the NFI and NIDCAP's capacities and reach thrive for years to come for newborns and infants and their families.

Reference:

Kaufman, S. B. \& Gregoire, C. (2015). Wired to Create: Unraveling the Mysteries of the Creative Mind. New York, NY: Perigee Books.

\section{Greetings from the Editor}

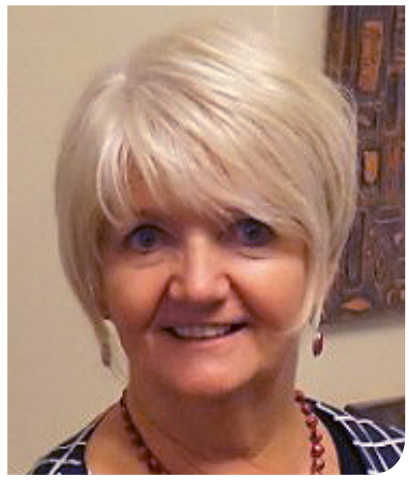

Kaye Spence, $A M$
Welcome to the second issue for 2020. What a year it has been so far. There have been many challenges for the NIDCAP community. Resilience is a prime focus at the moment.

This issue has a theme of reflection from our global community. There are a variety of interesting perspectives. Michiko Doi reflects on her journey as a NIDCAP translator in Japan, giving us a unique glimpse into her world. Bronagh McAlinden from Australia reflects on her observations of two newborn feeding episodes showing the importance of close observation. Ita Litmanovitz joins us from the Science Desk reflecting on the effects of COVID-19 through her examination of stress on the developing brain, and in our new Poet's Corner, Julia Giesen, NIDCAP Professional, reflects on her NIDCAP Training through her poetry. In our Family Voices column we hear a father's journey through the NICU with his twin daughters.
These manuscripts show the power of reflection, not only as a learning strategy but as a way of enriching the experience of the journey. We journey to Barcelona, Spain to hear about the work of the NIDCAP Training Centers and we travel to Cyprus in the Mediterranean to learn about developmental care initiatives. The Rimini team share their beautiful story of their using beauty to minimise stress in the NICU. Deborah Buehler, President of $\mathrm{NFI}$ shares her essay on what she sees as the strength of the $\mathrm{NFI}$ collective during these challenging times. The global spread of NIDCAP is evident with contributions from Japan, Australia, Canada, Israel, Italy, Spain, Cyprus and USA. We are certainly a global community.

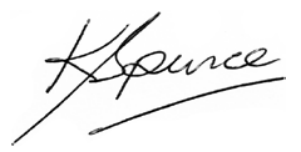

Kaye Spence AM

Senior Editor - Developmental Observer

Adjunct Associate Professor / Clinical Nurse Consultant

Australasian NIDCAP Training Centre / Sydney Children's

Hospitals Network / Western Sydney University / Australia

2 $2020 \cdot$ Developmental Observer 


\section{Putting Beauty at the Heart of the Healing Process}

Gina Ancora' ${ }^{1}$ Sandra Lazzari ${ }^{2}$, Natascia Simeone ${ }^{3}$

${ }^{1} \mathrm{Head}$ NICU, ${ }^{2}$ Chief Nurse, ${ }^{3}$ NIDCAP Professional

Newborn Intensive Care Unit, Infermi Hospital, Rimini, Italy

$\mathrm{N}$ ewborn babies in the Newborn Intensive Care Unit (NICU) often face physical, emotional and psychological distress. The parents also may experience emotional, psychological and spiritual suffering during this period, affecting their baby's development negatively. Therefore, the baby's development in NICU may be disadvantaged in three ways: their prematurity and the illnesses associated with it, the distress they experienced in the NICU, and the suffering of their parents.

There are two main causes of this distress. First, the use of high technology in the NICU can overwhelm and agitate small and fragile newborns and their parents. Second, hospitals with closed institution philosophies can perpetuate an unsupportive environment for parents. They may be denied ongoing opportunities to be with their newborn(s), as if they were visitors, hindering their emerging parenting skills and identity. This distress may be quite widespread.

How can healthcare systems and professionals address and reduce all this sufferance? Solutions may lie in reimagining how to educate the NICU staff. Specifically, education and support with a focus on the family and their development as well as on the design of the hospital space to be relaxing and individualized.

Each family in the NICU experiences their own unique journey. Humanity and beauty can be found in the stress and grief that many of them face. Grief can often create opportunities and space for sharing, healing and support.

Creating welcoming NICU environments offers opportunities for families to be at the center of the healing process, where they may feel supported and not so alone. Caring for the beauty of the NICU space offers an aesthetic element. It helps to communicate the importance of each person, by caring about them through the natural aspiration to beauty, especially their relationships with a new life. This attention helps to heal parental feelings of helplessness, fragility, resignation and fears of being unable to cope.

The humanizing initiative of putting beauty at the heart of the healing process follows an ongoing cultural change in attitude.

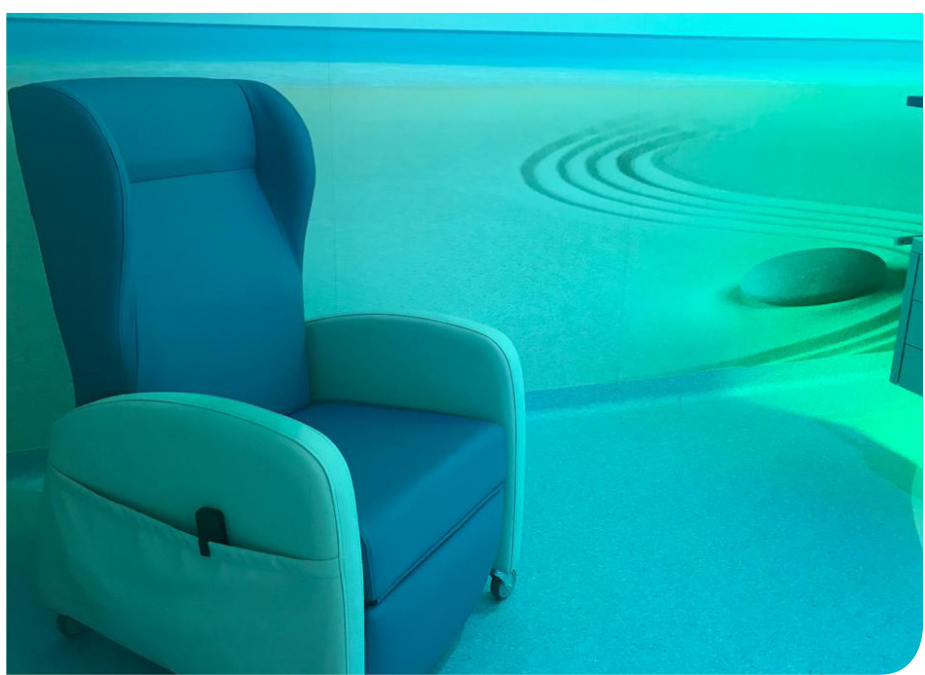

A backlit artistic panel in the NICU in Rimini created with support from the charity La Prima Coccola Onlus.

Each individual is cared for as a whole, including their family, while still considering their delicate stage of development.

Dostoevsky ${ }^{1}$ said "beauty will save the world", and in our case it will help to reduce the stress of the NICU environment for newborn infants and their families. It will produce long term benefits for the neurological, emotional, academic and psychological development of the child.

Important ways to create beauty within NICUs are to design clinical areas to be welcoming with comfortable furniture (both for the baby and their parents), offer pleasant views with natural imagery, use soft and indirect lighting, and maintain low noise levels. Implementing these changes in the care environment has proved to be effective, for example, in reducing the level of pain and the use of painkillers in adults.

In 1948, the World Health Organization (WHO) was already defining wellbeing beyond merely the absence of physical illness, but also in terms of quality of life. This approach in the hospital is complex and requires many skills: clinical, artistic and

\section{Developmental}

\section{Observer}

A semi-annual publication of the NIDCAP Federation International @ 2020. The statements and opinions contained in this newsletter are solely those of the individual authors and contributors and not necessarily of the NIDCAP Federation International. Articles from the Developmental

Observer, duly acknowledged, may be reprinted with permission. Please contact us at: developmentalobserver@nidcap.org.

Senior Editor

Associate Editors

Associate Editor

for Science

Column Editor
Kaye Spence AM

Diane Ballweg, APRN, CCNS, Deborah Buehler, PhD, Sandra Kosta, BA gretchen Lawhon, PhD, RN, FAAN, Maria Lopez Maestro, MD Jeffrey R. Alberts, PhD

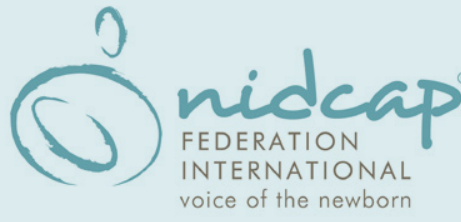

Contributions

We would like to thank all of our individual donors for their generous support of the NFI and its continuing work. 

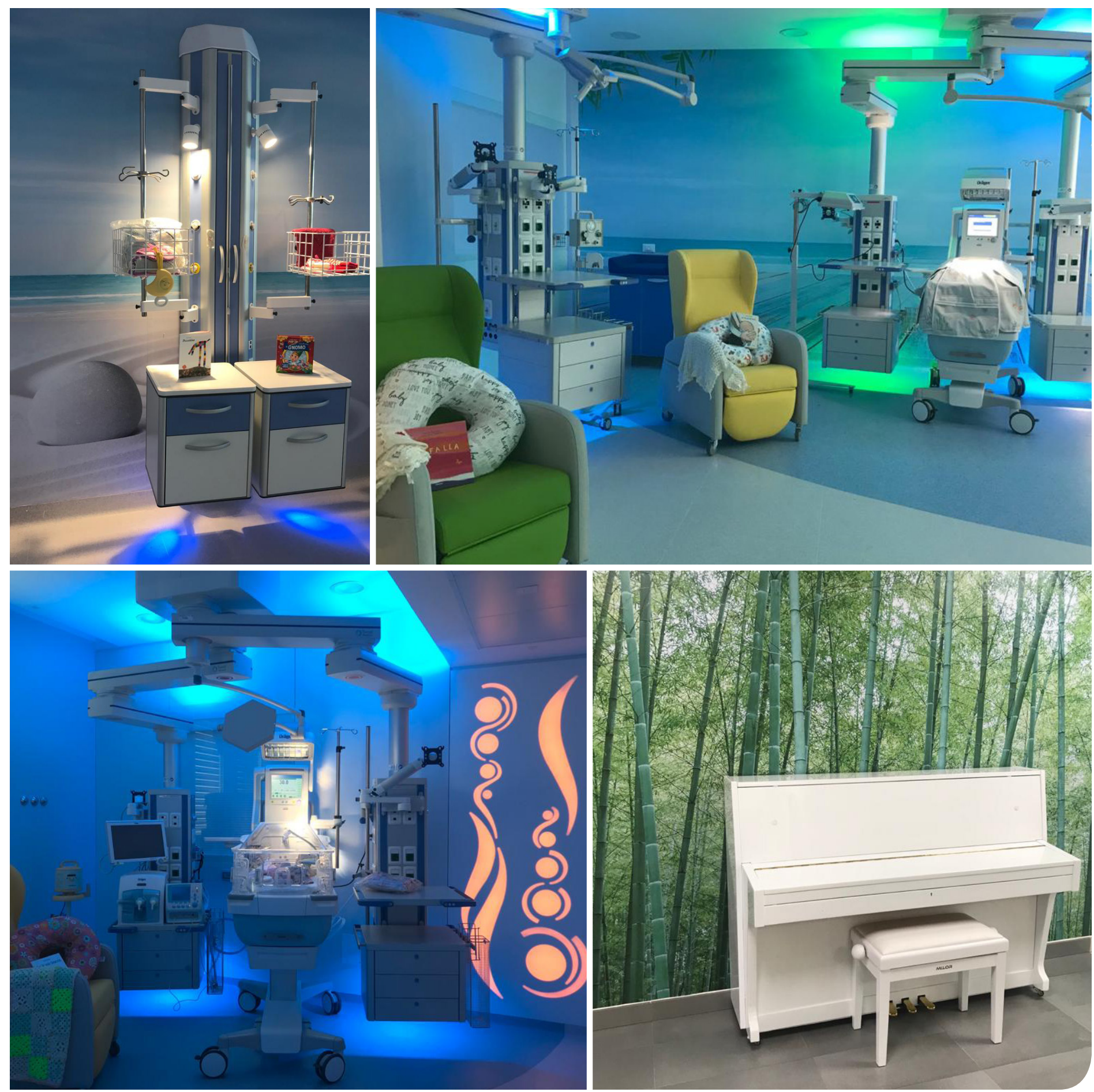

In order to create a more welcoming environment, La Prima Coccola Onlus works to fill the new Rimini NICU with pictorial spaces and backlit artistic panels throughout the clinical areas occupied by the babies and their parents.

technical. The goal of the families that volunteer at "La Prima Coccola Onlus", a charity founded to support the NICU in Rimini with the cooperation of hospital staff, is to draw on the WHO's vision. They work to fill the new NICU with pictorial spaces and backlit artistic panels throughout the clinical areas occupied by the babies and their parents.

Furthermore, work environments that include beauty as a requirement, contribute to the wellbeing of the staff. Being surrounded by beauty encourages an open attitude of listening and increased empathy with the babies and their families, producing positive outcomes and more efficient care.

Reference:

1. Fyodor Dostoyevsky, The Idiot. 
$\mathrm{O}$ ur story began early on the morning of July 18th, 2019 when I was awoken by a startling scream. My wife Nikki had woken up in the middle of the night to discover she was bleeding, a lot. Nikki was just four days into her 27th week of pregnancy with our twin girls. In a haze of sheer panic, Nikki waited in the car crying as we called our next-door neighbor to stay with Ben and Lily (our older set of twins) until Nikki's dad could drive from his home two hours away to stay with them. With our eldest in our neighbor's care, we rushed to Abington Hospital - Jefferson Health in Abington, Pennsylvania.

Nikki was immediately placed in the triage portion of the maternity ward. We felt as if our worst nightmare was coming true again, as another frantic visit 11 months ago ended in the tragic loss of our daughter Sophie at term when it was discovered that there were knots in her umbilical cord that had suddenly tightened. Thankfully, after what seemed like an eternity, the medical team were able to find heartbeats for both babies, and so far, they were doing fine.

The focus now turned to Nikki to try and ascertain the reason for the sudden heavy bleeding. In past ultrasounds, it was identified that Nikki had a very marginal placenta previa. Although the doctors had originally told us this would likely rectify itself in the next few weeks as the babies grew, without another known cause, they believed this was the likely reason. While the doctor prepared us for an emergency caesarian to deliver the girls, time passed, and after an hour or so the bleeding slowed down and panic was averted for the interim.

After a few hours in triage, Nikki was transferred to the maternity ward for additional monitoring where the conversation turned from an emergency delivery to the possibility of moving Nikki to a "Mom Unit" for the remainder of her pregnancy. That evening I drove the 10 minutes back to our house to check on the kids (and Nikki's dad). After speaking with Nikki and preparing for my return to the hospital early the next morning, I received a frantic call from Nikki telling me she started bleeding again and that I needed to get to the hospital as soon as possible for delivery of our girls.

As I walked into the maternity ward, I saw the Obstetrician (OB/GYN) outside Nikki's room; she was the same OB/GYN that delivered our eldest twins, and I took much comfort in that as we both knew her very well. Nikki's doctor told me outside her room that we had to move ahead and deliver the babies for Nikki's safety given the volume of blood she was losing. I recall tearing up and thinking to myself that I couldn't let Nikki see me crying as I had to be strong for her since I knew she was very

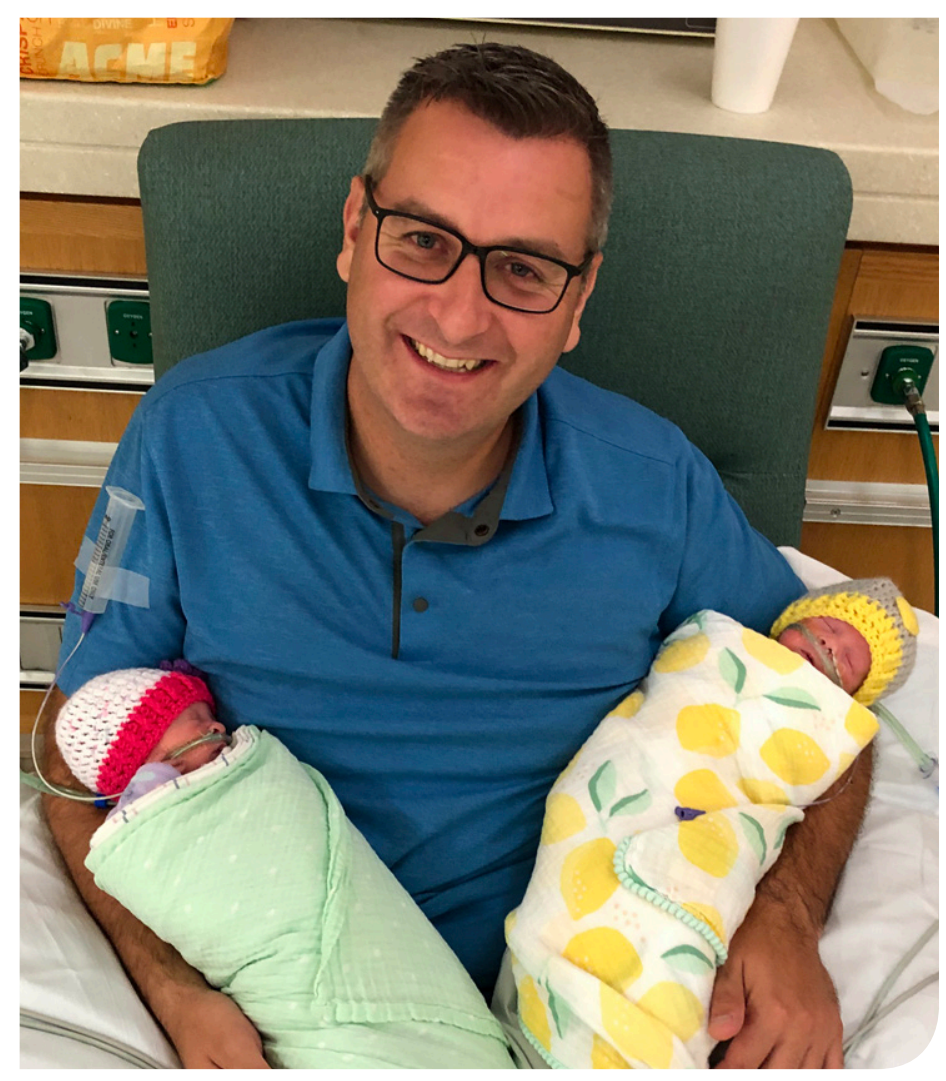

Proud Dad with Maty and Lucy at 33 weeks PMA.

scared. After taking a minute to compose myself, I walked into her room, held her hand, and the adventure began.

We were whisked off to an operating room and before I knew it, Lucile 'Lucy' Sophie and Matylda 'Maty' Maura had entered the world topping the scales at a whopping 2 pounds, 6 ounces (1179 grams) and 2 pounds, 3 ounces (1043 grams). Each baby had their own team working with them and I got a brief second to see each baby (and cut Lucy's umbilical cord!) before they disappeared to the NICU. I was genuinely surprised by how big they looked, or maybe long is a better description given how skinny they both appeared. In my head a 27 weeker was going to be tiny, and in the grand scheme of things they certainly were, but it was a small comfort to see that they resembled a fullterm baby much more than I expected.

After staying with Nikki as she moved through recovery and was transferred to her hospital room, I set off to the NICU to get an in-person update on Lucy and Maty. The NICU was already familiar to us, as our other set of twins, Ben and Lily were born 


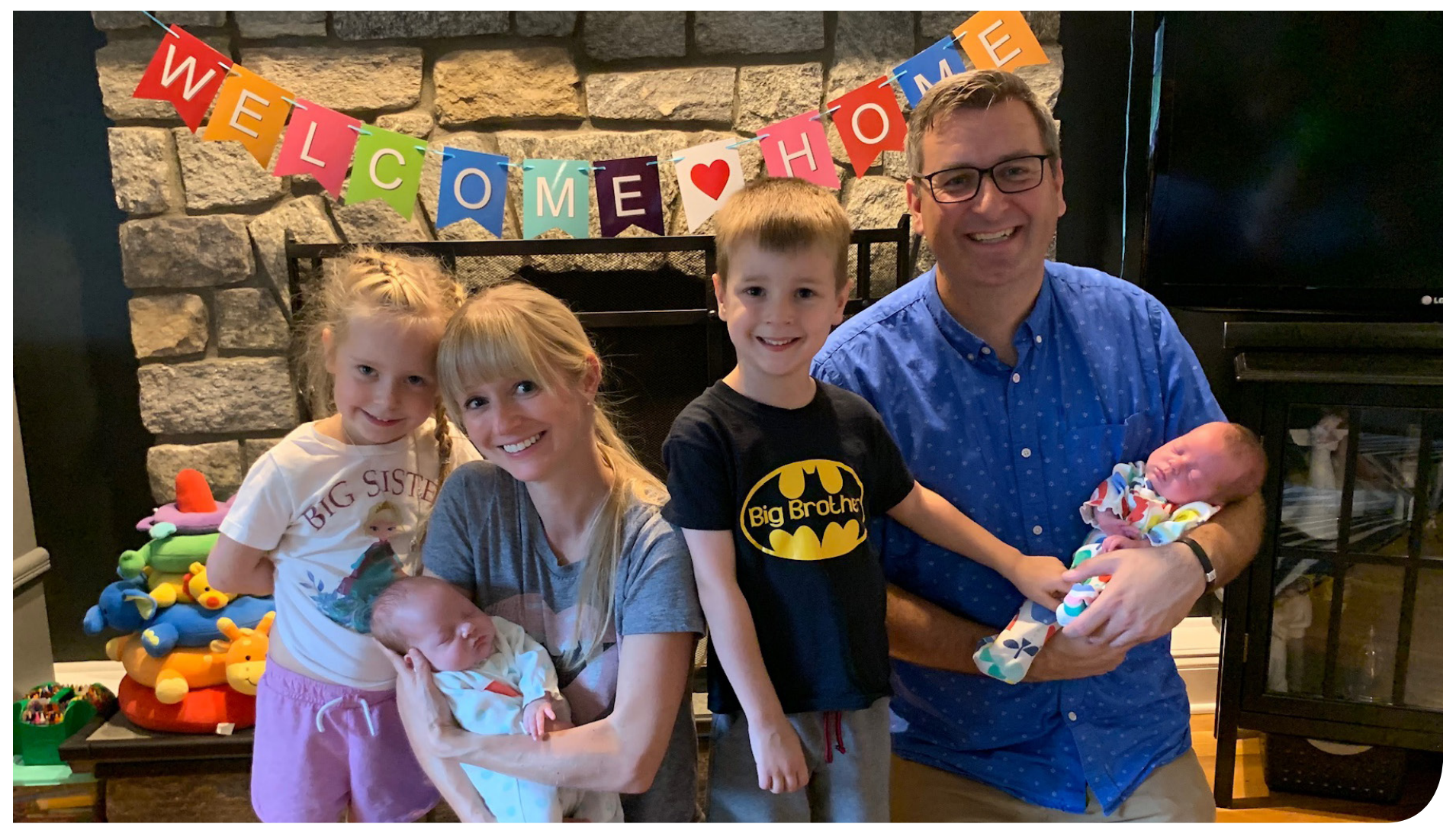

Bringing the girls home.

at 35 weeks, 6 days in the same hospital where they spent 5 days in the NICU. Their time in the NICU, however, was not due to prematurity. Ben had a broken humerus from a traumatic delivery, and Lily had low glucose levels. Thinking back on our first experience with the NICU as worried first-time parents, those 5 short days felt like a lifetime. Little did we know the months of NICU life that were to come.

When I arrived Maty and Lucy were in their incubators surrounded by medical equipment with all kinds of tubes and wires connected to them. They were stable, and according to their nurses, doing as well as could be expected. The array of equipment and sounding alarms everywhere was overwhelming - as a parent you want to protect your children from harm, and that day, I felt absolutely helpless.

For the first few days we could only touch them through the walls of the incubator, holding their tiny hands as their little chests rose and fell with each CPAP assisted breath. Finally, after two days, they were stable enough to be held. I still remember the image of Nikki holding them for the first time. After a troubling year for our family, she had never looked so happy.

At first our time in the NICU moved slowly with what seemed like little progress from day to day. In my limited experience of illness or hospitalizations, there are usually typically signs of change that either signal improvement or regression. In my NICU naivety, I was expecting a similar sign with the girls in those first few days or at least some indication that they were going to be ok. Obviously, no one can predict the future, but I longed for a crystal ball for a peek of what was to come, some indication that the long road ahead was going to ultimately end with all of us going home together, happy and healthy.

Both my wife and I have an extensive science background, so we questioned everything, wanting to understand the how and the why behind each and every decision and change in their care. We always made sure to be present for daily rounds so we could be part of the conversation and advocate for the girls. Personally, I became focused on the numbers on the monitors. Their heart rate, respiration rate, oxygen saturation - those were the numbers I lived by for three months. Initially every alarm was terrifying, who wasn't breathing, what were their vital signs?... was their oxygen saturation level dipping?... was I holding the girls incorrectly? Over time I came to understand that each alarm wasn't a cause for panic, just a signal to assess the situation and address any issues accordingly.

Being a small part of Maty and Lucy's daily care made a huge difference. I looked forward to just doing things like changing a diaper or taking their temperature; these small things in the crazy situation made me feel more like a normal parent in a far from normal situation. The highlight of course was holding them, feeling them breathe against your chest - they felt so small, so fragile, yet so incredibly strong and resilient.

Of course, the NICU experience is full of ups and downs. You hope for consistent steady progress, reduced breathing support, gradual weight gain and positive test results. Each battle that the girls won came with new challenges for them navigate; it truly is a rollercoaster. It was important to try and stay positive, but at the same time to temper your optimism and try to maintain an even keel so you could enjoy the progress without getting too down about the setbacks. 
Our NICU had a tradition of printing out signs to celebrate various milestones - a pound gained, a bottle finished, and so on. As a parent, as simple as it seems, you wanted to see those signs next to your child's incubator so badly. Given the layout of the NICU, we could see other babies ahead of ours in their journey. Although the plethora of signs at their stations were always a source of jealousy, they also gave us hope that our girls would someday soon reach these seemingly small but important milestones.

Slowly we began to chat with some of the other NICU parents. The more familiar a face, the less awkward we felt saying hi or chatting to them briefly without disturbing their privacy.

Those conversations helped. It's a unique experience and chatting to someone going through the same gamut of emotions was a welcome distraction.

In the initial weeks of our journey Nikki spent the day with the girls and I would go in for a few hours each evening after work to sit with them and hold them. Leaving them at the end of each visit was always difficult, hoping for an uneventful, alarm-free evening; yet our girls were never alone, and in many ways, neither were we. The entire NICU staff including the receptionists, the respiratory therapists, the doctors, and most importantly, the nurses who doted on them every day all became part of our family. Loving our children with us and for us, sending us pictures and updates in the middle of the night, talking to us about nothing and everything. They were fantastic and will hold a special place in our hearts forever.
As the girls progressed, we were able to play a bigger and bigger role in their care, feeding them bottles, changing their clothes, and my personal favorite - bath night. Despite the obvious physical improvements that the girls were making (weight gain, transitioning to a bottle, and breathing without assistance), our minds always turned to their development. Fortunately, our NICU had a Developmental Specialist on staff. She had spent some time with the girls throughout their stay, initially monitoring how they reacted to their care and feedings, but it was when she administered the Assessment of Preterm Infants' Behavior (APIB) test that I was really intrigued. The idea of the test initially seemed a little bizarre as I couldn't see how a preterm baby could possibly do any of the things being assessed. Yet, to my genuine surprise, each test elicited the predicted response, and it was immensely comforting to see that the girls were behaving as they should from a developmental standpoint.

After 75 days, the girls were finally given the green light to go home. Looking back on our experience in the NICU, we were incredibly fortunate for a relatively smooth journey and will always be indebted to the wonderful, caring staff we met and befriended. With their help, our girls have already overcome the greatest challenge of their lives and are now thriving one-year olds. Each day brings to light new facets of their personalities, and I can't wait to see who they become in the years ahead.

Kevin and Nikki live with their family and a very lazy basset hound in Hatboro, Pennsylvania.

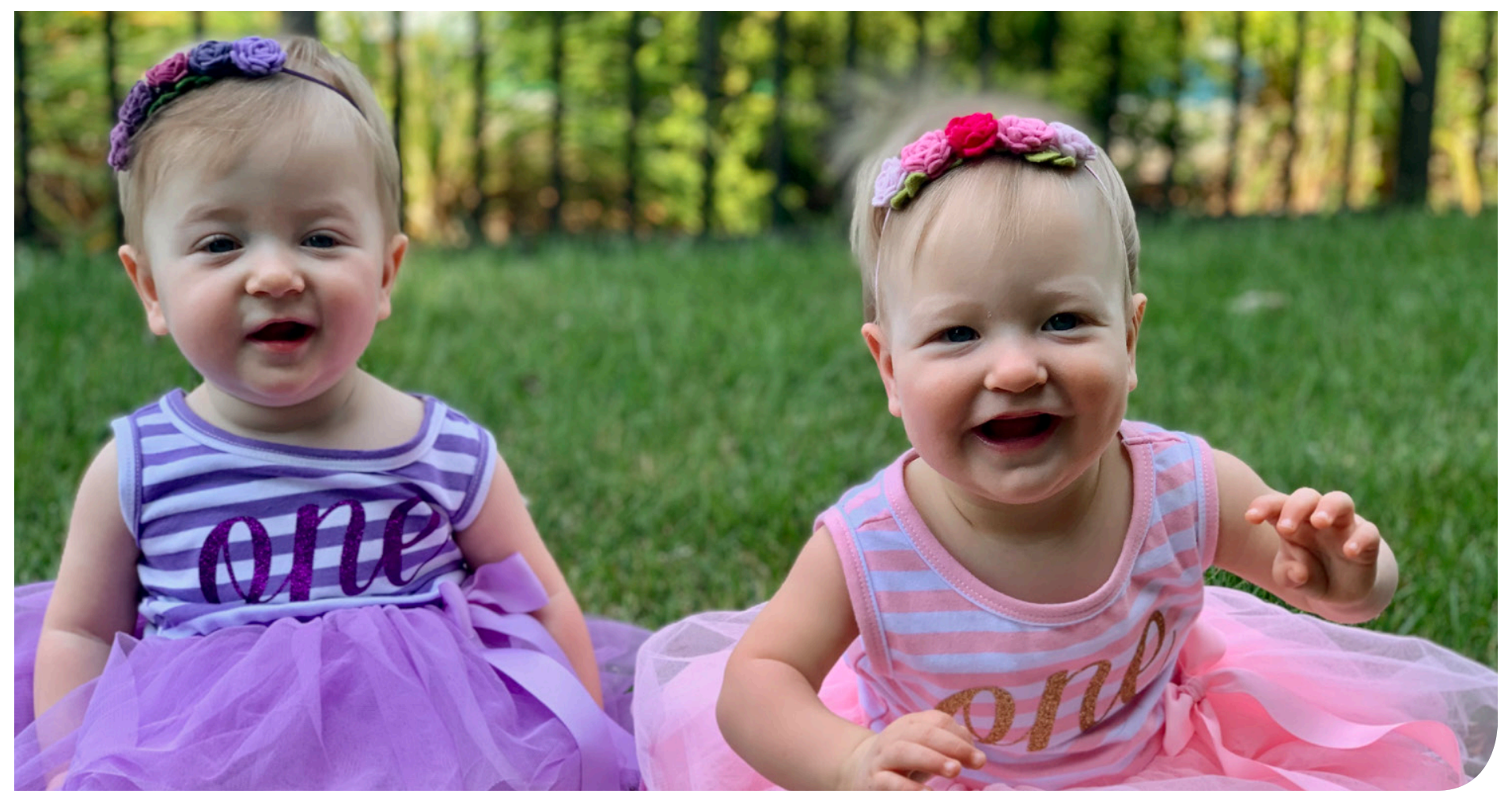

Maty and Lucy - one-year birthday (9 months adjusted). 


\title{
Reflections on Infant Feeding
}

\author{
Bronagh McAlinden (MPhil, BPthy (Hons))
}

Physiotherapy Department, Mater Mother's Hospital, South Brisbane, Queensland, Australia

Tn May 2020, I graduated from the Family and Infant

Neurodevelopmental Education - Level 2 (FINE 2) course. In Australia, the FINE program is a precursor to NIDCAP Training. This course enabled me to improve my knowledge and practical experience when working with preterm and critically ill newborns. I found FINE 2 challenged me, both as an observer and in a hands-on role, to look for and respond to the cues expressed by preterm babies. I learned to provide more individualized care to babies based on my observations of their cues and improved my ability to educate my colleagues and the families. As a physiotherapist my experience undertaking the Infant Feeding Module was particularly valuable. Feeding is not typically part of my role, so through FINE 2 I was able to observe babies feeding. I learned a lot about how challenging feeding can be for preterm infants. I would like to share my experience with infant feeding in the following observation and reflections.

\section{Reflections of a tube feeding}

I observed Mia for a tube feeding as part of my FINE 2 program. Mia, daughter of Katherine, was born at $25+4$ weeks gestation and was $36+4$ weeks corrected age when I observed her. Mia weighed 480 grams at birth and weighed 1758 grams at 36 weeks corrected age. I observed Mia in the afternoon. At the time of her feeding Mia was not rousing enough to try an oral feeding. As a result, Mia had a gravity tube feeding.

Reflecting on Mia's feeding, I felt quite comfortable watching her and this was no doubt reflected by her stable state and minimal signs of distress. In thinking about how this feeding could have been improved, prone positioning appeared as a strength for Mia in helping her settle, digest and maintain a flexed position with her hand up so she could self-soothe. Obviously being in this position (or full prone) on her mother, Katherine's, chest would have been preferable and I felt this was something that could be encouraged with Katherine when she was present. The use of a pacifier could be something to consider, however I appreciate that Mia was largely in a sleep state.

However, the way her nurse prepared her position and immediate environment within her cot, really assisted Mia to maintain a relaxed state and tolerate her feeding well. I also reflected on how I contributed to the noise around Mia when I was conversing with her nurse. This was something I wish I hadn't done, and highlighted to me how easy it is to become a bit complacent in these situations. I have found since beginning this course that I am much more aware of my speaking volume and those of my colleagues. I also try and move conversations away from the baby and demonstrate hushed talking.

\section{Reflection of an oral feeding}

I observed a second baby, Max, during an oral feeding to contrast difference in responses and behaviours between tube and

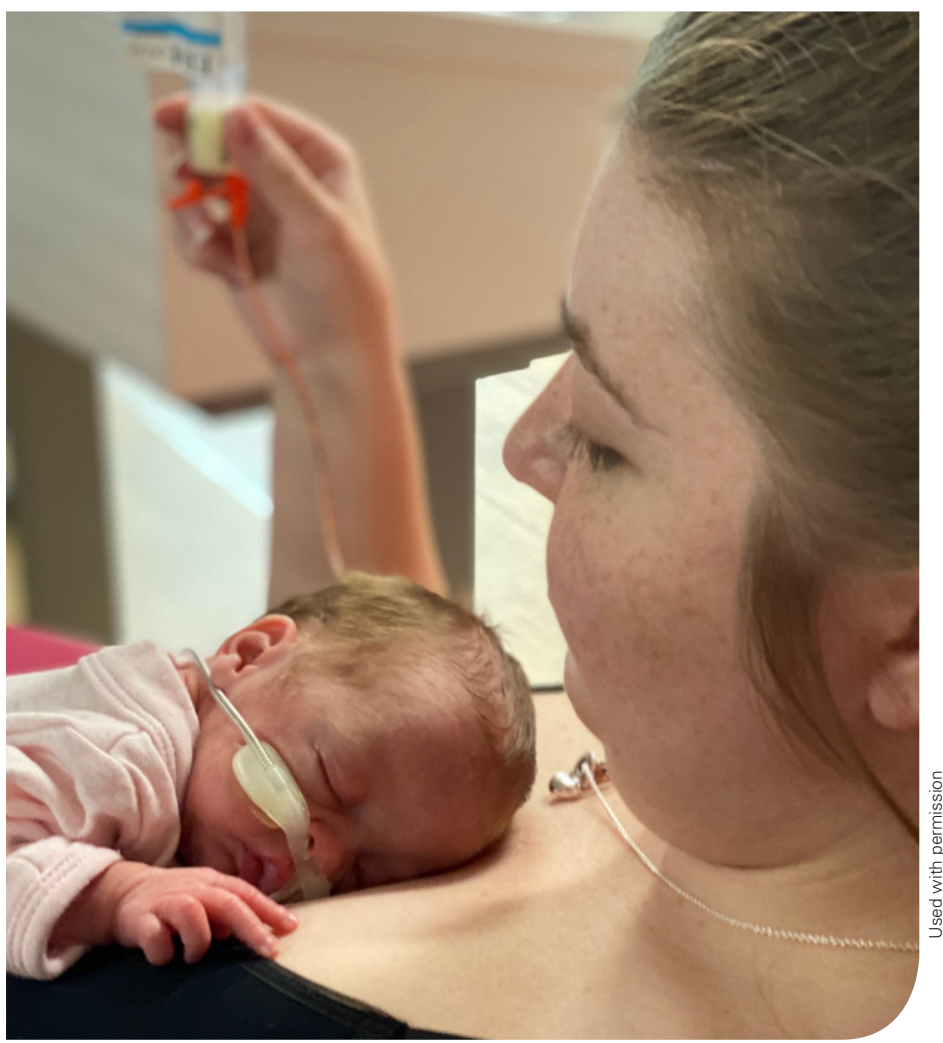

Tube feeding a newborn infant.

oral feeding. Max was born at $23+0$ gestation and was $41+0$ at the time of my observation. He was being nursed in the special care nursery in an open cot and still requiring High Flow Nasal Pressure (HFNP) at $5 \mathrm{~L} / \mathrm{min}$ in $0.25 \mathrm{FiO} 2$ at baseline. Max's feeding regime at the time was demand feeding (roughly four hourly). I observed Max for a bottle feed.

Reflecting on Max's feeding, I felt it could have gone smoother and reminded me how complex feeding is and how challenging it can be for a baby with existing vulnerabilities. I felt that in terms of preparation, although Max was demand feeding, the timing of the feeding delivered was probably slightly overdue. Max was clearly hungry and some of the energy and stress he spent prior to feeding may have been better utilized during his feeding, had it been given slightly earlier. The environment for Max's feeding, like Mia's, was busy. A quieter setting, with lightening reduced, may have also helped minimize Max's energy expenditure and stress prior to, and during his feed. I found that Max tended to pace himself, something he clearly needed to do to satisfy both his feeding and breathing requirements. This was interesting to see, but also made me realise how much energy goes into feeding for a baby with chronic neonatal lung disease (CNLD), such as Max, and also how challenging it can be to feed to a baby like Max. I did feel some concern regarding how his mother would cope with feeding, considering 
how little opportunity she had had to feed Max. It definitely highlighted the need to ensure that parents feel well-supported and comfortable with feeding, prior to taking babies home.

I found this course module to be one of the more challenging for me. I took the opportunity to get a deeper understanding to observe how Max handled his feeding. As with previous modules, a nice opportunity for contrast came out of my two observations, not only the way in which Mia and Max differed in their type of feeding, but also in how well each coped. Mia obviously had less of a challenge (and challenging time) with her tube feeding, compared to Max who had to work very hard to simply breathe and suck effectively. Both Max and Mia had significant challenges related to their prematurity and extremely low birth weight and unfortunately both babies were in a situation where access to their mother was limited. I took from the comparison the importance of getting Mia's mother involved in her oral feeding as soon as Mia was ready, to avoid the same difficulties that Max's mother was likely to have at the time of her discharge. I think from now on I will include feeding more readily into my education with parents from an early stage. By using some of the observations and reflections I have made in this module, I may be able to help parents become aware of signs of feeding readiness and intolerance. Hopefully this will give my sessions a more well-rounded approach in the future.

Although I found it less comfortable than other modules I'm glad I had taken the opportunity to observe feeding. A feeding (tube or bottle/ breast) is usually what comes after I see the baby in my role as a physiotherapist. I am very rarely present for the duration of a feeding, having moved on to other tasks and seeing other babies. Seeing how Max and Mia responded to feeding, a basic survival and key developmental skill, was really interesting and gave me a much better understanding of how

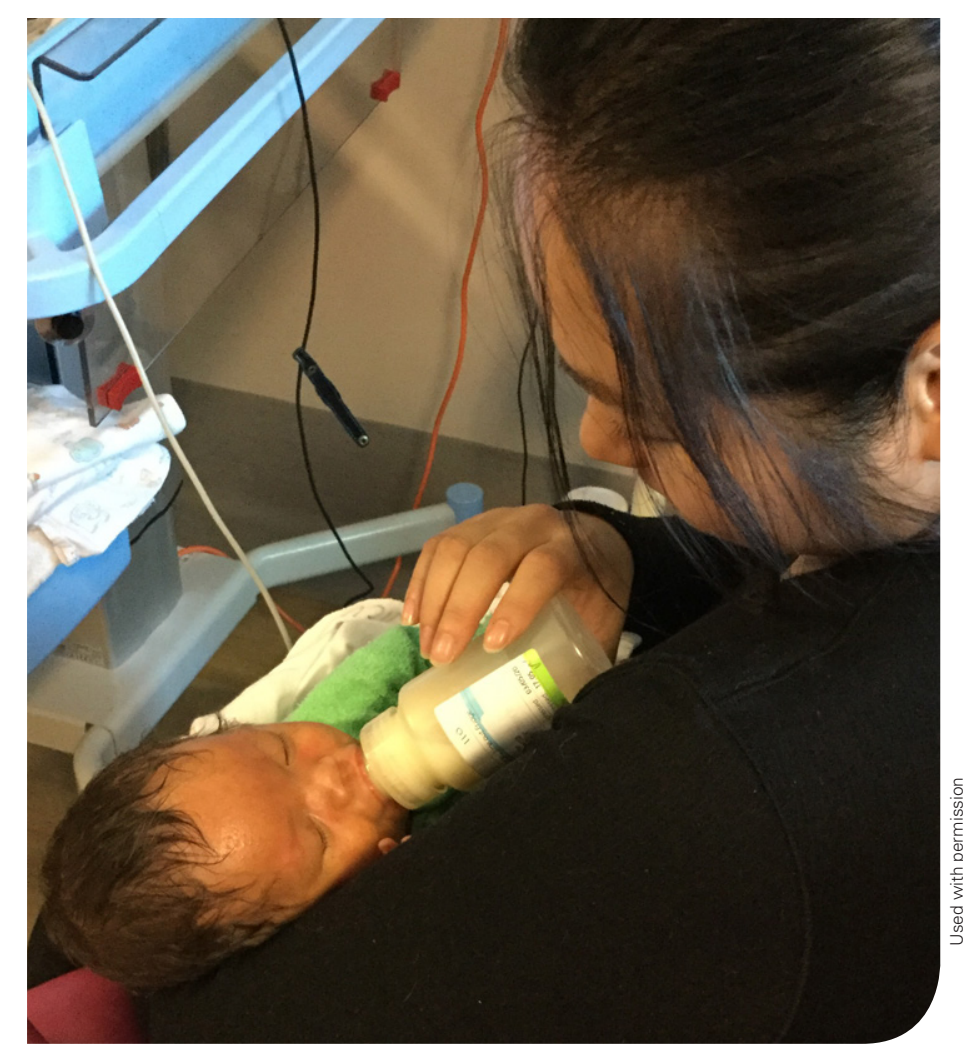

Mother bottle feeding her newborn.

challenging this can be for both parent and baby. This course definitely helped me gain better insight into the challenges and how a baby's stability and robustness during feeding can indicate a lot about how mature they are, thus adding another layer to my understanding of the impact of feeding on overall development and vice versa.

\section{Mission}

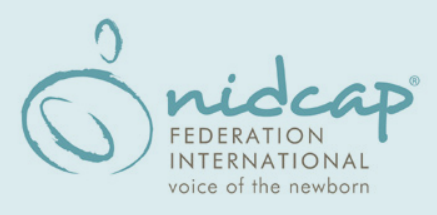

The NFI promotes the advancement of the philosophy and science of NIDCAP care and assures the quality of NIDCAP education, training, mentoring and certification for professionals, and hospital systems.

Adopted by the NFI Board, July 1, 2019

\section{Vision}

The NFI envisions a global society in which all hospitalized newborns and their families receive care in the evidence-based NIDCAP model. NIDCAP supports development, enhances strengths and minimizes stress for infants, family and staff who care for them. It is individualized and uses a relationship-based, family-integrated approach that yields measurable outcomes. 


\section{Global Perspective of Developmental Care - Cyprus}

Pani Pantelides, PT

Consultant Neonatal Physiotherapist and Early Intervention Specialist

Senior Faculty of the Family and Infant Neurodevelopmental Education (FINE)

NIDCAP Professional, NDT

C yprus is a small island situated in the south eastern Mediterranean. The Republic of Cyprus was founded in 1960, after decades of colonial British rule and it joined the European Union in 2004 and the Eurozone in 2008. Since the Turkish invasion in 1974 the island has been halfoccupied and the following article refers only to the situation in the area over which the Government of the Republic of Cyprus exercises effective control and where the Acquis Communautaire of the European Union is fully implemented.

There are two NICUs in this part of Cyprus: A Level III NICU, in the Archbishop Makarios public hospital in the capital Nicosia where 800-900 newborns are treated per year, and a Level IIB, in the general public hospital in Limassol that treats around 350 newborns per year. According to the most recent official data, the Rate of Preterm Births in Cyprus is 12\%, the Neonatal Mortality Rate is $1.9 / 1000$ and the Infant Mortality Rate is $2 \cdot 1 / 1000$. Annual births are between 8,000 and 9,000. Due to lack of community support services, babies spend longer in the hospital than they might where there are community nurses.

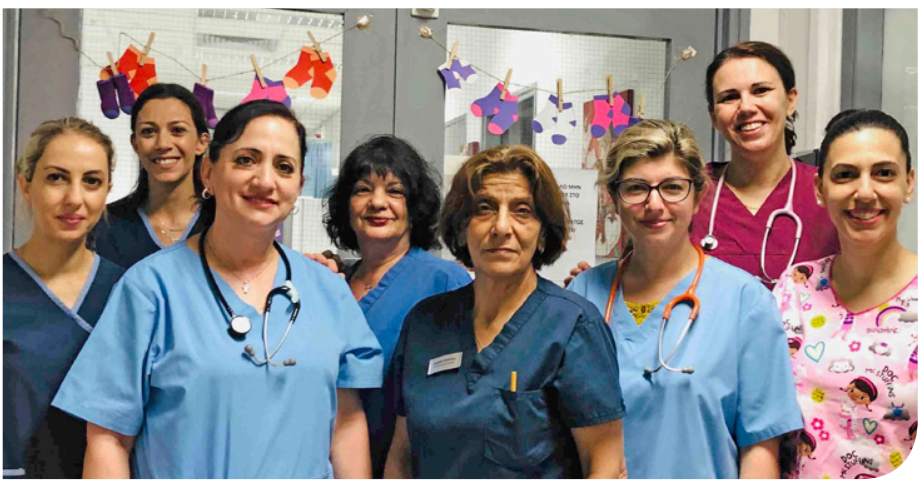

Limmasol team - left to right: Elena Vasiliadou, Ifigenia Smila, Maria Zeniou (NIDCAP Professional), Skevi Andorka, Christoulla Vasiliou, Eleftheria Konstantoulaki, Stalo Ioannou, Matina Lamari.

The NICU in Nicosia was founded in 1984, by Dr Andreas Hadjidemetriou, the first Cypriot neonatologist. With dedication and maximum personal effort he created the very first NICU in Cyprus from scratch. His vision was not only to reduce the mortality of sick and premature infants, but also to ensure the best quality of life for these infants. For this reason, he actively supported the implementation of developmental care and with his zeal and perseverance he inspired his successors to do the same. I had the privilege to work under Dr Hadjidemetriou's mentoring during my working term in the Archbishop Makarios Hospital (2007-2013), when we laid the foundation for developmental care. We are still collaborating today, on a voluntary basis, through the parents' organisation "Thermokoititha Agapis" ("Incubator of Love"), despite his retirement and my shift to the private sector.

My fulltime collaboration with the Nicosia Unit, as Developmental Care Leader, began in 2007, since the gradual training of all staff on the implementation of developmental care, became one of Dr Hadjidemetriou's priorities. On the occasion of my own training to become NIDCAP Professional (2008-2010) and Dr Maria Zeniou's NIDCAP training (2010-2012), the Nicosia Unit initiated close collaboration with Dr Inga Warren, former Director of the UK NIDCAP Centre at St Mary's Hospital in London. Dr Warren has generously been providing consultation to our unit through various baby observation workshops based on the NIDCAP model, for all the staff. Under her valuable guidance in 2009, we managed to create the first protocols of care and in 2010 we began a new institution, the "Parents School", which was about weekly meetings between me and parents, in order to support their communication and interaction with their babies. The "Parents School" evolved gradually and in 2013, a psychologist and a nurse were added.

In 2010, we were pleased to run the first kangaroo care training for members of the staff with Dr Nils Bergman. Since then, we are making consistent efforts to increase the number of babies who enjoy "skin to skin" care.

The turning point in developmental care implementation was in 2012 with the Foundation Course: Individualised Family Centred Developmental Care run by Dr Warren, Ms Bond and myself as an assistant. After that course we decided that it was best to take actions to decentralize developmental care, in order to make more people responsible for preparing strategies, taking actions and initiating staff education.

For this reason, we established a Central (Scientific) Multidisciplinary Developmental Care Committee and a sub-committee of 13 nurses that were responsible for spreading knowledge to the rest of the staff. In order to support staff education in using the new protocols of care we named an intensive care room as the "educational nursery room" in which the staff was expected to practice according to the new protocols. The Educational Nursery Room helped everybody to change their mentality in 


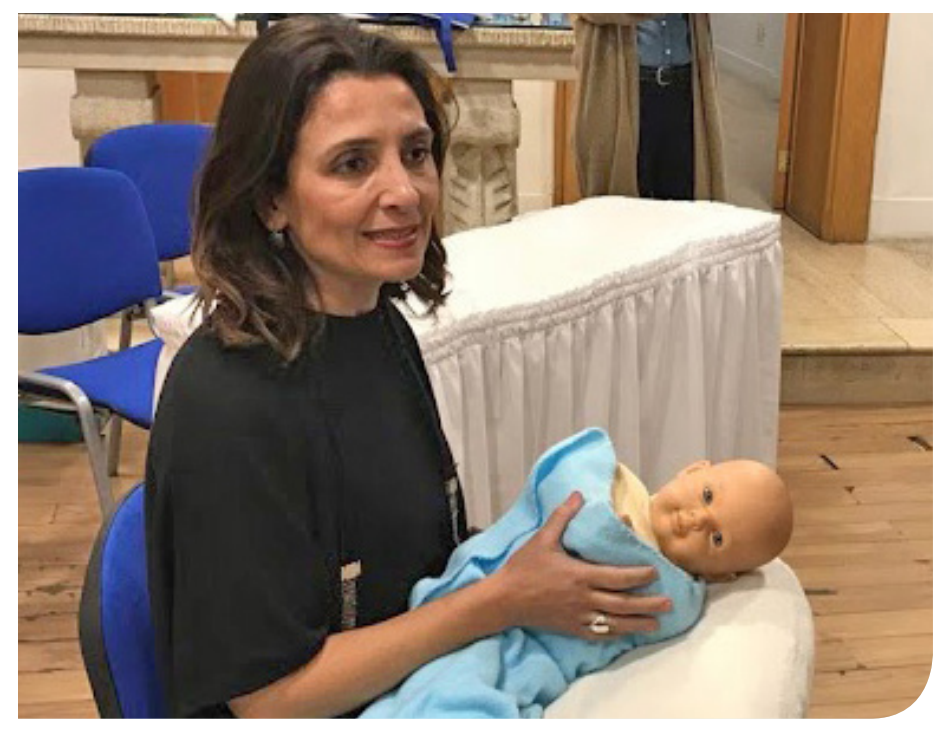

Pani Pantelides - Consultant Neonatal Physiotherapist and Early Intervention Specialist demonstrating positioning using a doll.

caregiving, improved practical skills in developmental care and minimized the gap between training and practical skills.

Unfortunately, due to overcrowding and understaffing of the NICU, (1 nurse for 4-6 newborns in intensive care and 1 nurse for 8-10 newborns in special care) the above measures faded and the standard application of protocols became inconsistent. Finding ways to train our staff was always a big challenge for us and the shortage of nurses inevitably reduces training time.

FINE (Family and Infant Neurodevelopmental Education) was the next big step in family centred care for both NICUs thanks to the Director of the Ministry of Health's Nursing Services, Andreas Xenophontos, who passionately supported FINE training and has put it under his auspices. This course is mostly taught in Greek by myself and Dr Maria Zeniou under the direction of Dr Inga Warren. The goal is for all staff in the NICUs, to follow FINE 1 and for those possible, FINE 2. Until recently, five staff members have completed FINE 2 and three more are in the final stage. We have also been able to work with Dr Warren to introduce FINE 1 and FINE 2 in Greece. Unfortunately, due to the COVID-19 pandemic we had to postpone our second FINE 1 training.

In Nicosia, despite the difficult conditions mentioned above, some basic elements of NIDCAP implementation have been achieved. There are measures taken towards comfortable and developmentally supportive handling, positioning, limitation of noise, light and other environmental stimuli and protection of sleep. Moreover, some first steps have been made for pain management with the use of special pacifiers for premature babies and positioning aids and a protocol to use sucrose or human milk is in development. Sometimes stressful/painful procedures take place during Kangaroo Care, the implementation of which lately has been expanded in the intensive care rooms as well. Parents' interaction and involvement in their baby's care is slowly progressing. Until recently, parents were allowed to be in any room of the NICU for only one hour at noon and one hour in the afternoon. Resistance to parents' participation, partly driven by concerns about overcrowding (the intensive care rooms are extremely cramped), is gradually being overcome with FINE training. As a result, since the beginning of 2020, parents are welcomed for one hour at noon and for two hours in the afternoon in the intensive care rooms and for 12 hours (7:00-19:00) in the special care rooms. Care giving from parents is allowed only in special care and includes only feeding, bathing and kangaroo care. The goal is to enable parents to be in all rooms in the NICU any time on a daily basis and take care of their babies completely. Last but not least, the Archbishop Makarios Hospital in Nicosia is working towards becoming a Baby Friendly Hospital with steps to support breast feeding in the unit and the use of human milk.

The Limassol NICU was upgraded from Level IIA to IIB, in 2018 and is fortunate enough to have a full time NIDCAP Professional, Dr Maria Zeniou, as Developmental Care leader, who in addition to her medical duties, leads the Developmental Care team which includes a FINE 2 trained developmental physiotherapist and members of the nursing staff who have attended the FINE I course. The continuous presence of a specialised physiotherapist is crucial for the newborns' neurodevelopment and the training of the parents for the post NICU period. In addition, all the staff is duly trained in order to control and minimize environmental stimuli.

Remarkable effort has been made in Limassol to implement family centred care. Parents are welcomed 24/7 and they take full care of their babies from the moment they come out of the incubator. They are guided for Kangaroo Care on a daily basis and maternal breastfeeding is encouraged from birth as the Limassol Hospital is close to becoming a Baby Friendly Hospital. Moreover, there is a protocol to use sucrose or human milk during painful procedures and there is always someone available to support and comfort the newborn. All necessary care giving procedures are planned in order not to interrupt newborns' sleep.

Our next big step towards family centred care in Cyprus is the upcoming renovation of the NICU in Nicosia. With this renovation, among other things, a resting area will be created for parents with the possibility of sleeping and preparing simple meals and more bedside space will be available for a kangaroo care chair to fit and for parents to be more involved in their baby's care. In addition, there will be an upgrade of the NICU's sound insulation.

None of the above would have been achieved without the generous support of the parents' organization, "Thermokoititha Agapis" ("Incubator of Love") which organizes and finances all staff training regarding developmental care, provides the two NICUs with developmental care equipment and has taken over, in collaboration with the Ministry of Health, the renovation of the NICU in Nicosia. Last but not least, the full membership of "Thermokoititha Agapis" in EFCNI proved to be crucial and extremely valuable, not only for the implementation in Cyprus of the European Standards of Care for Newborn Health: Standards on Infant and Family Centred Developmental Care (2018), but also for the negotiations with the Ministry of Health and other stakeholders, on the matter. 


\section{My NIDCAP Journey as an Interpreter}

Michiko Doi, BA

Freelance Japanese - English Conference Interpreter

\section{Introduction}

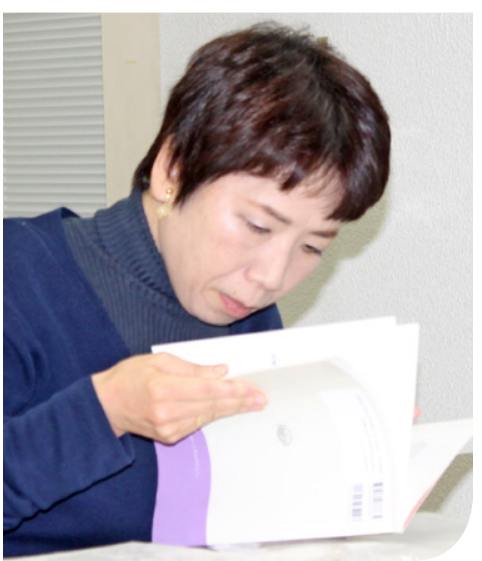

Michiko Doi

Thirteen years ago I had the opportunity to go to Tokyo, Japan with Heidelise Als to participate in a special seminar on developmental care. We were introduced to Michiko Doi who not only provided the professional translation of our lectures, but remained with us throughout our entire stay providing both interpreting and cultural guidance as needed. Little did I realize the lifelong professional and personal relationship that would evolve between us.

Michiko provides her insight into some of the difficulties for respected and experienced neonatal professionals to absorb new perspectives as NIDCAP trainees. She has demonstrated enormous patience as she interprets our complex discussions on some of the very subtle and nuanced aspects of caring for infants and families. As Michiko states, there is often more than mere translation required to communicate many of our NIDCAP terms and concepts. Michiko is the most flexible yet sturdy bidirectional bridge for our NIDCAP training communication. This involves both language and its inseparable cultural contexts. She has been indefatigable in her support of me from early mornings through late evenings, including professional work and social gatherings, from my arrival in Japan until my departure year after year.

Not only has Michiko provided her excellent service as an interpreter for the NIDCAP work in Japan, she has become the informal national advisor and counsellor as well as champion of all those involved in this work. While I have had the privilege and joy to be the NIDCAP Master Trainer for Japan articulating the voice of the newborn, Michiko has been my Japanese voice, for which I am most appreciative of her time, patience and trust.

gretchen Lawhon, PhD, RN, FAAN

Clinical Nurse Scientist with Newborn special care associates, pc at Abington - Jefferson Health NIDCAP Master Trainer with West Coast NIDCAP and APIB Training Center

A s I begin to write this article, I can't help but think of all the healthcare professionals around the world who are in the midst of the very difficult fight against the new coronavirus. They have their own families and friends as well as themselves to care for, and yet they are giving all they can to save people afflicted. My sincerest gratitude and respect goes to them.

Their dedication, however, is not only in times of emergency. It is constant - so constant that people may take it for granted. Childbirth also tends to be taken for granted. It is regarded as something that just happens, often without any problems. Now I know that it is not, especially when a baby is born early for some reason, and that is when everybody involved strives to provide the best possible care in their respective capacities. My experience as an interpreter in the NIDCAP trainings in Japan has taught me this.

I am not in the healthcare field. I am a Japanese-English interpreter by profession. Recently, in response to the growing need of international interactions in healthcare, I have often been asked to serve in healthcare-related conferences and technical visits. The NICU, however, had been an unknown world to me until I first stepped into one in 2007.

What I am about to share with you are the observations of a complete outsider. This outsider, however, has a keen interest in people, especially in a growing child as a biological and social being. So I knew even before actually becoming involved in the NIDCAP training as an interpreter that I was going to enjoy it. My encounter with NIDCAP and the journey which followed have been a truly rewarding and inspiring experience for me.

\section{The Beginning}

It was in Nagasaki in 2004 that I met Dr Akiyama, then a professor of Orthopaedic Surgery at Nagasaki University Hospital, when he organized a conference on early developmental intervention for high-risk newborns. As is always the case, I asked for relevant information such as the speakers' CVs, their presentation materials and recommended literature. These are 


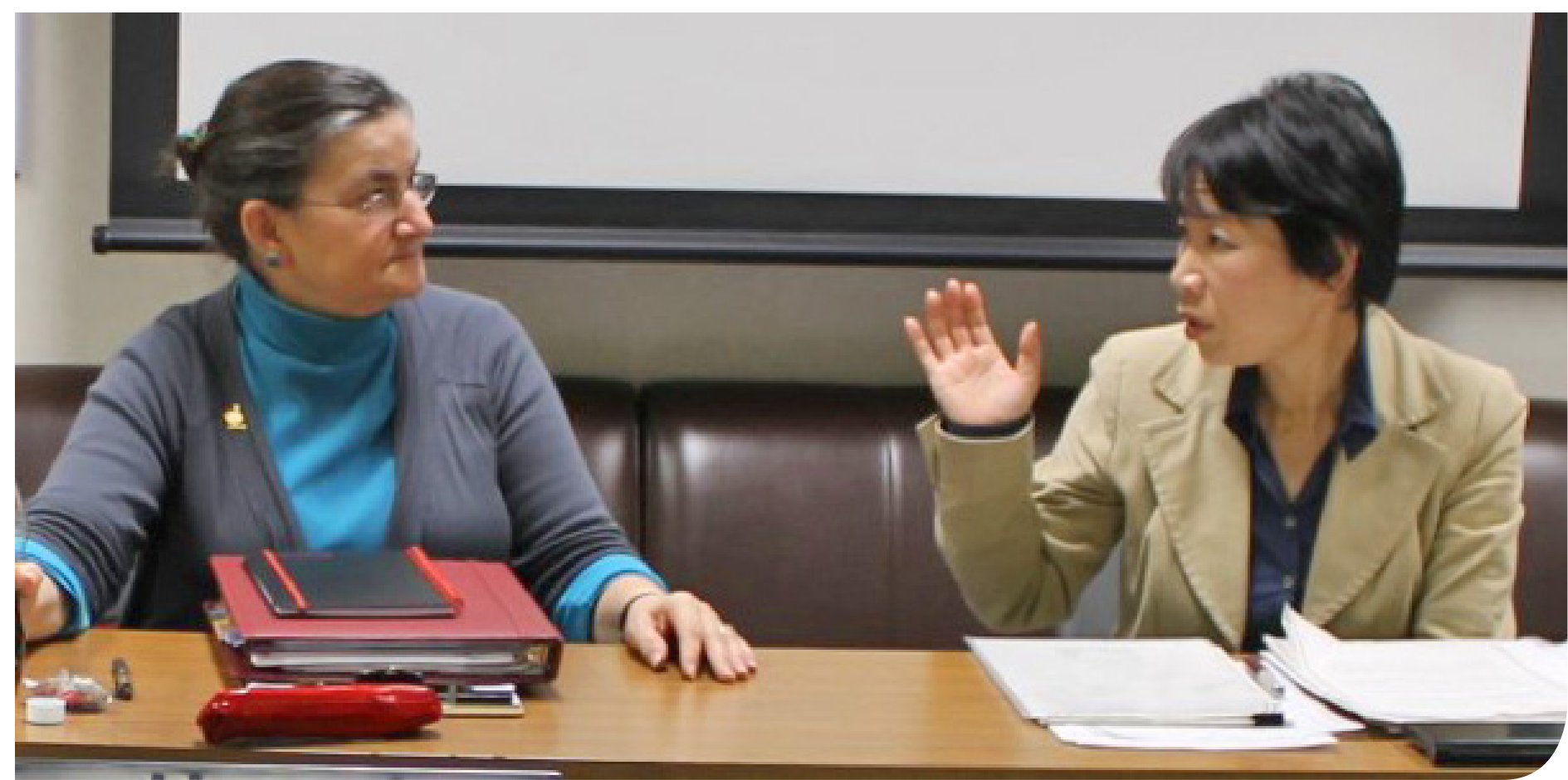

gretchen Lawhon and Michiko Doi.

very important for interpreters to make good preparation for the day. I usually start by grasping general ideas of the topic through reading all information available, then familiarise myself with the terms and expressions in both Japanese and English, and also do some research to deepen my own understanding of the topic. In the process, I came across some key concepts and terms, and among them was the name 'T. Berry Brazelton'. It turned out to be quite a challenge for me mainly because the information available in Japanese was rather limited. With the kind help of Dr Akiyama and his colleagues I survived.

In July of 2007 an opportunity presented itself to translate at a seminar with Dr Heidelise Als and Dr gretchen Lawhon at Tokyo Women's Medical University Hospital. This offer came from Dr Ohgi, once a collaborator with Dr Akiyama and then a professor of physical therapy at St Christopher's University in Hamamatsu. It was a two-day seminar including both lectures and demonstrations, which, in fact, became the first milestone for NIDCAP in Japan.

I remember the room was packed with an enthusiastic audience and filled with expectations for something innovative. Dr Nishida, then a professor of neonatology and the organiser of the seminar, later confessed he himself had little idea about what to expect because NIDCAP, at least then, was largely unknown in Japan. Therefore, there was almost no relevant information available in Japanese. All I had with me was the power point presentations prepared by the speakers, which had kindly been provided well in advance. I studied them very hard. Dr Als and Dr Lawhon were kind enough to answer the many questions I had to ask for clarification.

The fruit of this seminar was evident; it generated a momentum to move forward with NIDCAP.

\section{As a Companion}

In 2009, the first NIDCAP professional training began at Tokyo Metropolitan Hospital, Bokuto, for four trainees with gretchen. I don't think I need to go over the process here. So, instead, I would like to share some of my experience as an interpreter during the training.

The interpreter is supposed to help fill the gaps, or become a bridge in communication. Like any two languages, Japanese and English are different from each other in many ways. I usually find technical terms are easier to cope with because they usually have a one-on-one match in any two languages, so the interpreter's work is mainly to memorise. The NIDCAP terms and expressions, however, have more nuances. You really have to think what word or expression is most suitable in a given context, especially knowing that your translation will probably be used for some time in the future. Some terms in the Observation Sheet needed more than translation. We even asked gretchen to physically demonstrate them so that we could clearly grasp the link between the Japanese translation of the terms and their meanings!

Communication doesn't rely only on languages. Perfect translation doesn't always guarantee quick communication. In the training, professional backgrounds play a big part. Experienced, caring trainers like gretchen and Joy Browne have wide and profound insight into gaps arising from different backgrounds and they are prepared. The trainees, on the other hand, are likely to be trapped by such gaps, especially when they are trying to see something familiar to them in the different light. Of course, they have good reason to be. They struggle because their knowledge and experience interfere with the absorption of new perspectives. This creates a gap. 
There are also gaps stemming from differences in various systems in society including healthcare. With the word 'NICU', for instance, the picture that you may draw in your mind may be quite different from someone else's. What exists in one country or hospital may not exist in another; what is possible in one country or hospital may not be so in another. Gaps can be much more complex. So we have to be conscious of the possibility of such gaps and work towards a common understanding, and the interpreter walks the process as a companion. The beauty of all this in the training is that often this kind of struggle leads to a better understanding of the subject, and more importantly it nurtures a better relationship between the trainees and the trainer, among the trainees themselves and among all involved including the interpreter. It requires time, patience and trust in what you do regardless of the roles. I have witnessed many moments of such connectedness, and I am always impressed and supported by the nurturing attitude which dominates the team.

Currently in Japan there are nineteen NIDCAP Professionals and four are in training, involving seven hospitals. Five are in training to become trainers. How exciting!

\section{Thoughts on Universal Values in NIDCAP}

Much of my NIDCAP experience has been new to me, but I've never felt anything about it remote or irrelevant. NIDCAP, at its core, has some universal values which all humans can relate to and benefit from. Let me mention just a few.

Observation may appear to be a passive activity, but it is not. Fully committed observation like in NIDCAP can reveal so much so deeply. It is an active listening. It is from there that we gain an understanding and develop ideas and thoughts and eventually translate them into action. Reflection is another form of observation, that is, to observe your own thoughts and feelings, which I think is very important for everyone.

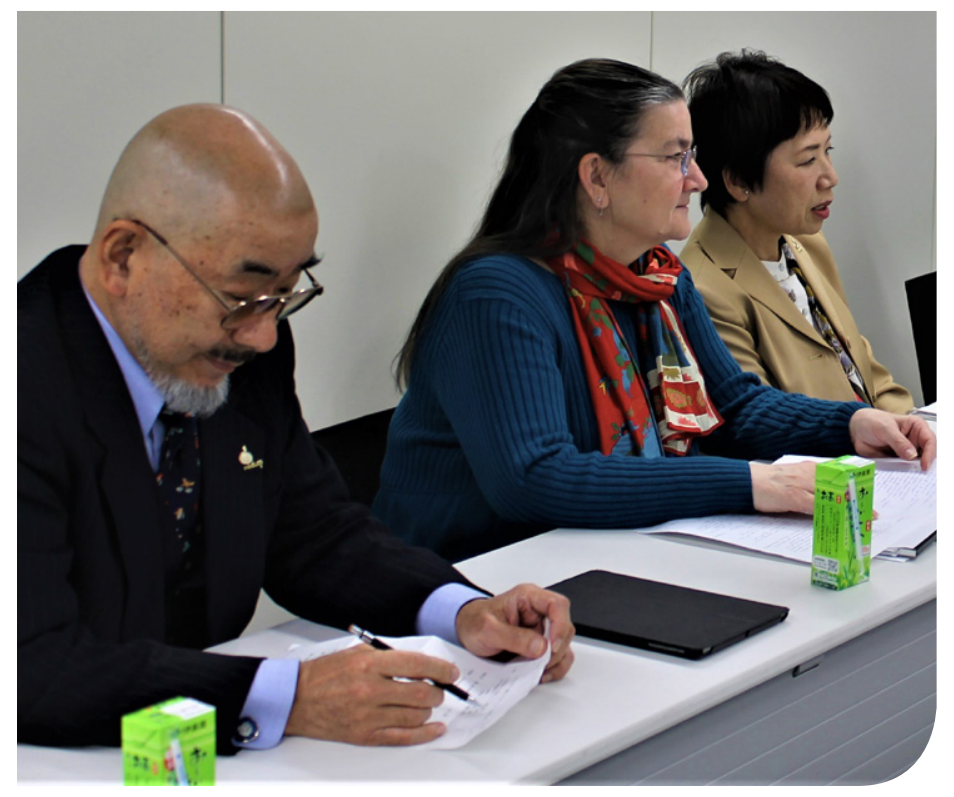

Dr Hiroshi Nishida, Dr gretchen Lawhon and Ms Michiko Doi.
In some cultures like Japanese culture, correcting weaknesses is more emphasized than acknowledging strengths. NIDCAP tells us we all have strengths to build upon from which to grow, however small we may be. 'Small' in this case can refer to the physical or to ability and capability. NIDCAP also reminds us that we grow in relationships.

Subtlety is another characteristic of NIDCAP. As an interpreter, I always need to be conscious of it and have solutions. Whenever I am tempted to think that there should be an easier way of describing something, I quickly remind myself that simplification in words may result in the dilution, if not loss, of the real meaning. While languages can open up so much space for positive communication, they also have limits when they are used just as signs and labelling for convenience. In this sense, the interpreter is just a bridge, and it is all up to the people on both ends whether they walk cross it to meet or not. Of course, I, as an interpreter, want to be a good strong bridge.

\section{Towards an End and Beyond}

In Japan, the training of NIDCAP trainers is underway and we are hoping to see the first Japanese NIDCAP trainers certified within the year. A national training centre with a multihospital structure is also in development. When all this has been achieved, my work as an interpreter will end. Sad personally, but for Japan it's really a huge celebration for the babies and their families, NICU staff, hospitals and society at large.

Dr Nishida, the honorary chairperson of Japan Developmental Care Research Association (JDCRA), has long been the principal author of 'Scientific Basis of Clinical Neonatology', one of the most valued and widely used textbooks in the field in Japan. A very important section was added to the latest 2018 edition: synactive theory and NIDCAP. It is brief but extremely significant because it is read by not only medical students but also students in nursing and other healthcare disciplines. They may not see its significance right away, but at least they know there is such an approach. The section concludes with the following remark:

"...developmental care skills and knowledge integrating NIDCAP as a pivot will be put into practice more widely in (Japanese) NICUs in the near future."

Remarks made by a Japanese neonatologist left a deep impression on me. He said, "Our unit has achieved the country's best survival rate for some years. We are proud of this, but we know it is not enough. We cannot say, 'You are fine and ready to go home, so good-bye,' when we know their lives will go on much longer. NIDCAP may provide us with a clue as to what action to take to achieve a better prognosis."

The JDCRA, the engine of NIDCAP in Japan, has updated its Website. Although most of it is in Japanese, you may still get a feel for what's going on in this part of the world.

I feel I have left out so many important people who deserve much credit in building the initial foundations of NIDCAP in Japan. I can only hope that the readers will have the opportunity to meet at least some of them in future NFI meetings. 


\title{
The Gold Standard for Excellence in Newborn Individualized Developmental Care
}

\author{
Model of the NIDCAP Nursery: From Self-Assessment to NIDCAP Nursery Certification \\ (Deborah Buehler, PhD, Sandra Kosta, BA, Heidelise Als, PhD, September 2018)
}

The figure graphically describes the relationship of training and support opportunities to nursery change from conventional care to consistently well-integrated NIDCAP care. It depicts the roles and relationships of newborn nursery components and the support opportunities offered to nursery professionals and staff engaged in this change process.

The infant and family are depicted at the nursery's core, cared for by the professionals and staff within the nursery and hospital. The hospital is understood as part of a greater community, a community from which infants and families come and to which they hope to return. The core of the figure shows the infant-parent relationship as it moves from one of infant isolation from the parents (Conventional Care; bottom) to one of full emotional and physical integration of infant and parents (NIDCAP Care; top) within the nursery.

PROCESS of NIDCAP CARE IMPLEMENTATION

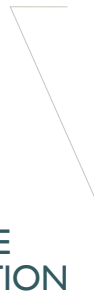

Consistently Well-Integrated NIDCAP Care

\section{Model of the NIDCAP Nursery}

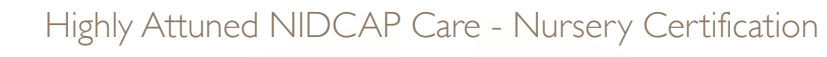

\section{Nursery \& Hospital}
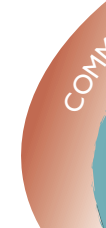

Variable NIDCAP Care

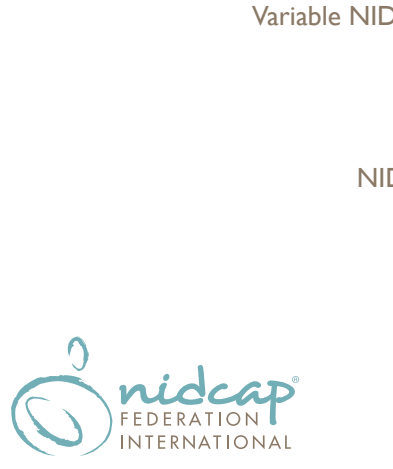

(c) NIDCAP Federation International, March 2018

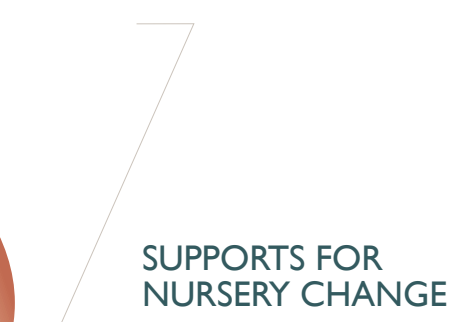

Continued Mentorship for Self-Assessment, Reflection, Education and Training

NIDCAP \& APIB Training

for Core Teams and

Nursery Assessment Review

Introductory/ Foundational Education

(e.g., NFI Nursery Foundation Education, FINE, and other NFI-Endorsed Conferences \& Courses) for all Professionals \& Staff

Interdisciplinary (incl. Parents) Goal Setting and Planning

Conventional Care

Nursery Self-Assessment: Identification of Strengths \& Challenges

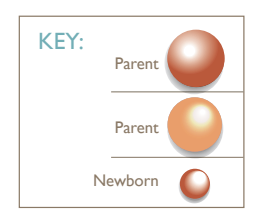

D. Buehler, S. Kosta, H. Als 
NIDCAP TRAINING CENTERS WORLDWIDE

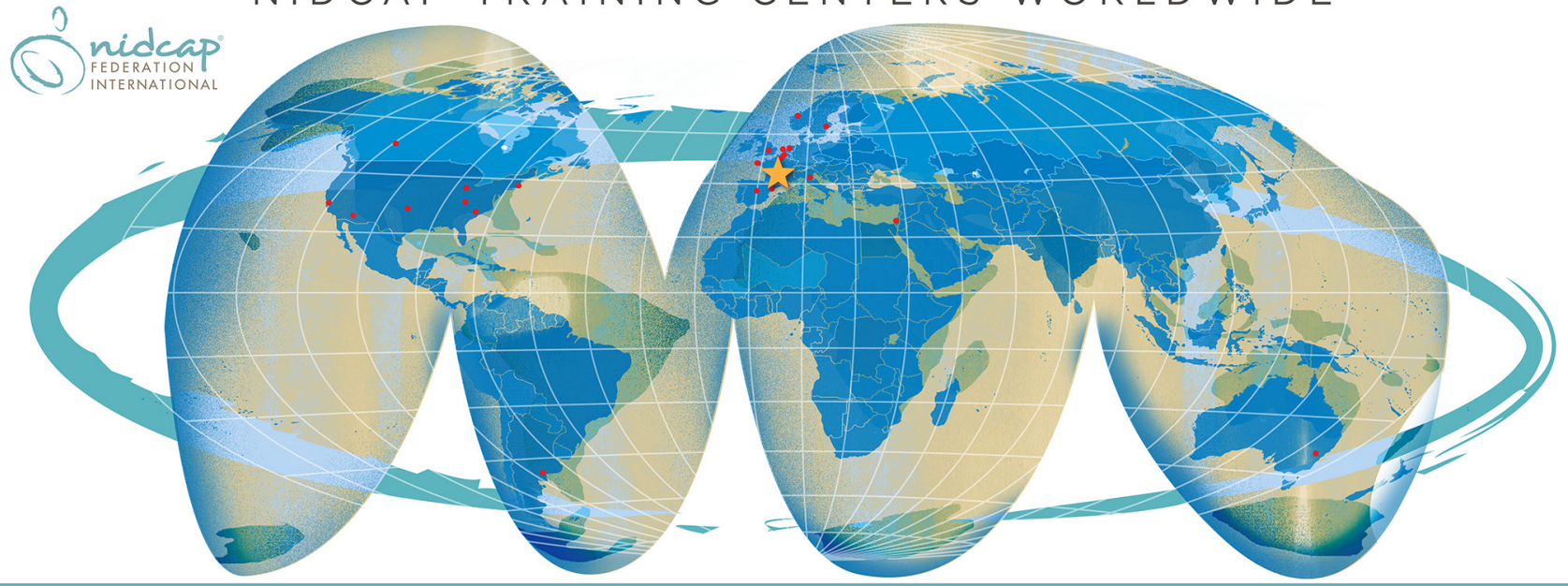

\section{NIDCAP Training Centers Around the World}

\section{The Barcelona NIDCAP Training Center}

The Barcelona NIDCAP Training

Center was opened in December 2011 at the same time as the Hospital 12 de Octubre NIDCAP Training Center in Madrid. The entire process of making the center ready was possible due to the collaboration between both hospitals and the tireless support of Graciela Basso, MD and Heidelise Als, PhD.

$\mathrm{C}$ urrently our center has two sites: the Hospital Vall d'Hebron in Barcelona and the Hospital Dr Josep Trueta in Girona. The three NIDCAP trainers are Fatima Camba, Estrella Gargallo and Josep Perapoch. Our goal is to offer NIDCAP training in hospitals of neighboring countries and, at the same time, contribute to the implementation of a NIDCAP-based model of newborn care in all hospitals within Spain.

Collaboration is likely the key word that best defines us as a center. Collaboration is one of the main values of our activity. Our challenges include the lack of time and financial resources, and perhaps this is a reason that has helped us to take part in some collaborative projects. Some of our projects are listed below, as they may serve as inspiration for other teams:

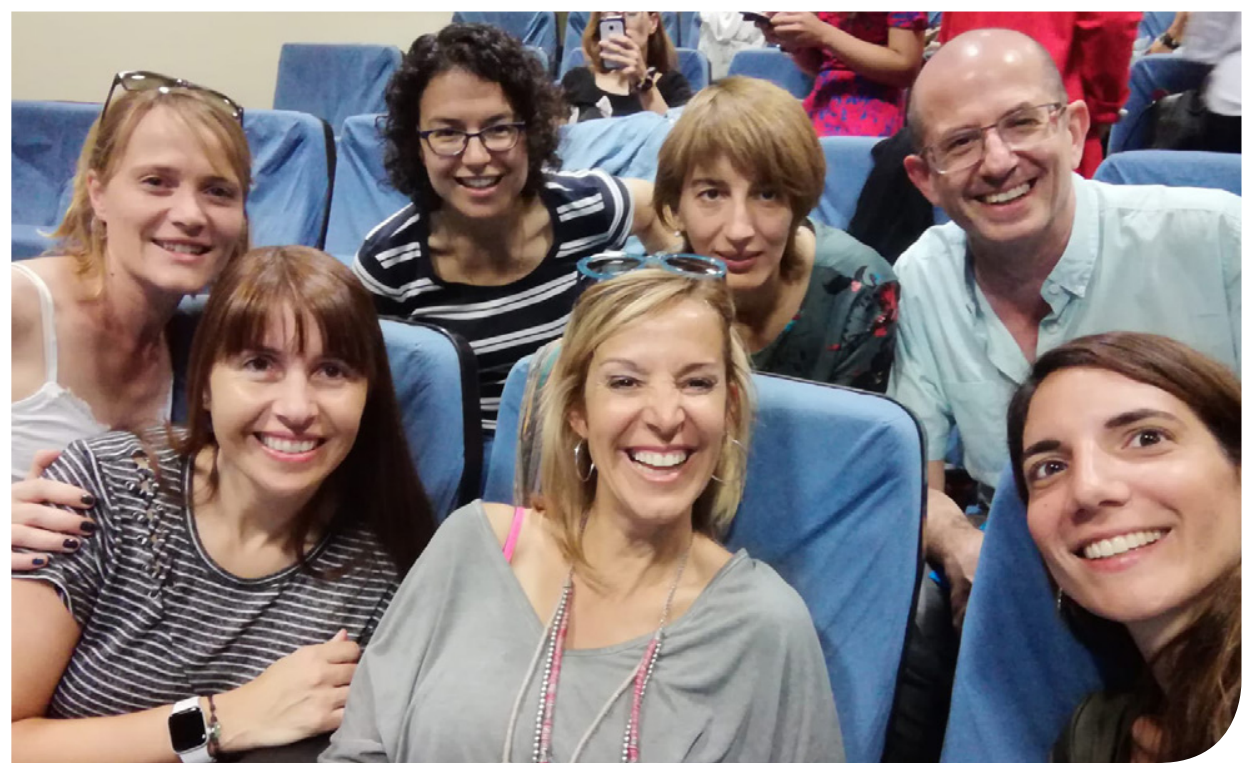

Barcelona NIDCAP Team

- With professionals and friends at the 12 de Octubre Hospital in Madrid, we collaborated through the Hera Project in broadcasting and training projects for developmental care throughout the country. We also collaborated in different research studies.

- With other hospitals of the Catalan Institute of Health and support of administration, we established a working group for the application of NIDCAP-based newborn care in all hospitals (PADEICS-NIDCAP working group). The Catalan Institute of Health is a hospital system providing care for approximately $45 \%$ of the very low birth weight newborns in Catalonia.

- With the groups of parents and professionals of working group hospitals, we held a workshop in 2016 to define the nine lines of 
improvement in individualized newborn care focused on development and the family. This document is the basis of all the improvement actions that have been used to work together during the last four years.

- Through collaboration with professionals and families, the "Germans" project to facilitate the inclusion of sibilings was started. (https://youtu.belamiUQHiS1Ls)

- With other hospitals and training centers of the Iberian Peninsula, we collaborated in eight editions of the "NIDCAP Iberian Meeting".

- Collaborating with administration and the university, we promoted development of a Guide for Parents of Premature Newborns, which is distributed in all hospitals.

As NIDCAP has no limits, our projects and dreams are being renewed. These are the challenges we would like to achieve in the near future:

- Work closely with the Hospital Sant Joan de Deu, the other large Barcelona hospital that is currently in the process of accrediting itself as a training center, to facilitate the application of NIDCAP in all the hospitals of the country.

- Incorporate a new professional NIDCAP Trainer to our team.

- Obtain administration support for training to achieve the availability of
NIDCAP Professionals in all hospitals.

- Repeat a working day with families. This is currently scheduled for November 17, 2020, yet may be rescheduled due to the Coronavirus pandemic.

- Gain the ability to apply the FINE2 training program.

- Finish a project started two years ago to offer introductory training in developmental care in an online format.

\title{
The Gold Standard for Excellence in Newborn Individualized Developmental Care
}

\author{
What All Newborn Infants and Their Families Deserve
}

\begin{abstract}
Newborn Individualized Developmental Care and Assessment Program (NIDCAP)
The Newborn Individualized Developmental Care and Assessment Program (NIDCAP), originated in 1984 by Heidelise Als, $\mathrm{PhD}$, is the only comprehensive, family centered, evidence-based approach to newborn developmental care. NIDCAP focuses on adapting the newborn intensive care nursery to the unique neurodevelopmental strengths and goals of each newborn cared for in this medical setting. These adaptations encompass the physical environment and its components, as well as, the care and treatment provided for the infant and his or her family, their life-long nurturers and supporters.
\end{abstract}

\section{Assessment of Preterm Infants' Behavior (APIB)}

The Assessment of Preterm Infants' Behavior (APIB) (Als et al., 1982) is a comprehensive and systematic research based neurobehavioral approach for the assessment of preterm and fullterm newborns. The APIB provides an invaluable diagnostic resource for the advanced level clinician in support of developmental care provision in a nursery.

\section{NIDCAP Nursery Program}

The NIDCAP Nursery Program provides a comprehensive resource for the self- evaluation by a nursery system of its strengths and goals for integration of NIDCAP principles into all aspects of their functioning. Highly attuned implementation of NIDCAP care for infants and their families, as well as for the staff, in a developmentally supportive environment is a goal as well as a process. External review and validation by the NFI may be sought when a nursery feels it has achieved this distinction. Nurseries that have achieved NIDCAP Nursery certification serve as a model and an inspiration to others. For information on the nursery self-assessment resources as well as the certification process and its eligibility requirements, please see: www.nidcap.org; and/or contact Rodd E. Hedlund, MEd, NIDCAP Nursery Program Director at: nidcapnurserydirector@nidcap.org or 785-841-5440. 


\title{
Understanding the biologic effect of stress on the developing brain, and insights from the COVID-19 pandemic
}

\author{
Ita Litmanovitz, MD
}

Neonatal Department, Meir Medical Center, Kfar-Saba, Israel, Affiliated to Sackler school of Medicine, Tel-Aviv University, Tel-Aviv, Israel

Target article: Nist MD, Harrison TM, Steward DK (2019). The biological embedding of neonatal stress exposure: A conceptual model describing the mechanisms of stress-induced neurodevelopmental impairment in preterm infants. Res Nurs Health, 42:61-71. DOI: 10.1002/nur.21923

$\mathrm{T}$ he exposure to cumulative stress during critical neurodevelopmental windows early in life is a major unresolved challenge of modern newborn intensive care. In sharp contrast to the soothing environment of the womb, life-saving care provided in the Newborn Intensive Care Unit (NICU) exposes preterm infants to numerous painful and stressful interventions while separated from their mother.

The experience of repetitive exposure to stress places preterm infants at risk since significant maturational processes take place in the fetal brain during the second half of gestation. These include synapse formation (synaptogenesis), programmed cell death (apoptosis), proliferation of glia cells, and the beginning of myelination. As a result of premature birth, these processes occur in a time span when the preterm infant is hospitalized in the NICU. The protection afforded by the intra-uterine environment is no longer available, leaving the infant's developing brain vulnerable to different environmental stressors.

Studies that explored the impact of increased exposure to stress factors in the NICU, ${ }^{1,2}$ demonstrated alterations in brain neural connectivity, increased apoptotic processes that led to decreased regional brain volume and delayed maturation of the white matter at term age. Decreased regional brain volumes were found in former preterm infants even at seven years of age. ${ }^{3}$ Furthermore, a growing body of evidence, from both animal and human studies, indicate that stress experienced during the fetal and neonatal period is associated with substantial long-term neurodevelopmental morbidity. ${ }^{4}$

Despite the increasing evidence regarding the impact of stress on brain development of preterm infants, the mechanisms underlying these short- and long-term developmental influences remain largely unexplored. In the reviewed article, Nist and her colleagues present a new conceptual framework: The Neonatal Stress Embedding (NSE) model. They put forward an explanation grounded on the biological effects that newborn stress exposure in the NICU might have on short- and long-term neurodevelopment. The authors hypothesize that stress affects brain structure and function through alterations in four biological systems: the immune system, the autonomic nervous system
(ANS), the Hypothalamic-Pituitary Axis (HPA), and gene expression. These four systems interact with each other and most importantly, they can be modulated by both pre-natal and postnatal environmental variables like parental stress and maternal interaction (Figure 1).

The NSE conceptual model might be appealing to clinicians since it is consistent with known concepts of the developmental origins of health and illness. The Biological Embedding of Childhood Adversity Model ${ }^{5}$ postulates that early life stress such as childhood maltreatment, neglect, and violence, affects subsequent adult health outcomes. It provided the theoretical framework for the NSE model presented by Nist and colleagues in this review.

Fetal and/or neonatal inflammatory processes have been long associated with adverse neurodevelopmental outcomes in the perinatal literature. ${ }^{6}$ Inflammation is actually considered a common underlying mechanism in the multifactorial origins of several morbidities related to prematurity, such as bronchopulmonary dysplasia (BPD), retinopathy of prematurity (ROP) and necrotizing enterocolitis (NEC). Studies from both adult and neonatal animal models have revealed that chronic stress responses are associated with systemic inflammation. Newborn animal models further suggest that exposure to stress directly activates nervous system cells called microglia, known to play a role as primary regulators of immune responses in the brain. However, studies assessing the effect of stress on the immune function in preterm infants are still missing.

The involvement of both the autonomic nervous system (ANS), and the Hypothalamic-Pituitary Axis (HPA) in stress responses is well documented. Their integration into the NSE model therefore seems logical, yet not thoroughly studied in this age group. In newborn infants, exposure to stress results in increased sympathetic and decreased parasympathetic activity, as measured by changes in heart rate variability (HRV). Limited evidence from infants affected with sepsis suggests that decreased parasympathetic activity measured by HRV is a predictor for future neurologic impairments in preterm infants. However, the change in HRV might only be a marker for central nervous 
FIGURE 1. Neonatal Stress Embedding Model. ANS, autonomic nervous system; HPA, hypothalamic-pituitary-adrenal. (Adapted from Nist et al. 2019).

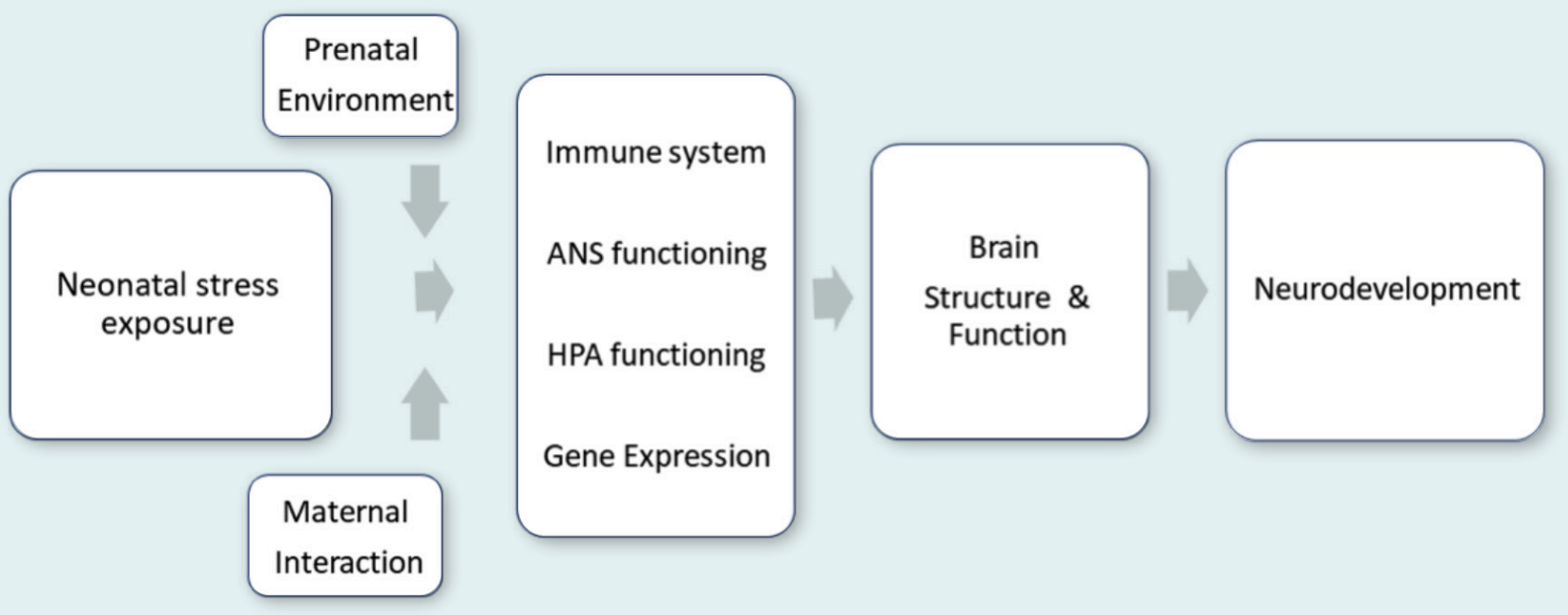

system involvement, rather than the actual cause of the neurologic insult. Chronic stress exposure is also known to cause repeated activation of the HPA axis, resulting in glucocorticoid resistance. Salivary cortisol levels measured before and following exposure to a stressor were lower in preterm as compared to term-born infants. Changes in the HPA response were demonstrated at school age and were associated with cognitive and attention problems.

Many of the mediators linking stress exposure and neurodevelopment are, in turn, mediated by epigenetic changes in gene expression occurring postnatally, as discussed in detail by Jeff Alberts in a recent issue of the Developmental Observer. ${ }^{8}$

The article by Nist and colleagues provides a comprehensive review on the topic of newborn stress and its impact on preterm infants. The article utilizes accepted models of the developmental origins of health and illness to shed new light on the impact of stress on preterm infant brain development. Thereby, it underlines the need for implementing caregiving approaches aimed at reducing and modulating infants' exposure to stressful stimuli and experiences at the bedside - as postulated by NIDCAP-based care - to improve the outcomes of preterm infants.

The limitation of the model is that the evidence base of the proposed concept is not strong enough, as it consists mostly of studies of human adults and of animal studies. However, gaps in evidence surely provide opportunities for new areas of research. Studies that will explore and test the suggested model might help to identify infants at risk as well as interventions needed based on their risk profiles.

The authors emphasize the role of nurses in practice changes (perhaps because the paper is published in a nursing journal) however, optimization of neurodevelopmental outcomes should be the priority for all clinicians caring for preterm infants. Therefore, the model presented might be meaningful for all health caregivers in the NICU - including decision and policy makers -when adopting practices that reduce stress in the NICU.

Reviewing this article in the midst of the COVID-19 pandemic presented a welcome opportunity to reflect on this topic. It assisted me, as a neonatologist, to better cope with the challenges generated for hospitalized infants, families, and health care professionals. During the last months, the lived experience of a global pandemic has been extremely stressful for parents, families, and healthcare professionals; stress that might adversely affect the outcome of the preterm infants.

Within these extreme circumstances, in order to keep infants and health care providers safe, some NICUs have adopted policies that drastically separate these medically fragile infants from their parents. It appears that some of the new guidelines implemented as a result of the pandemic lack a comprehensive perspective, and seem to disregard the basic understanding that parental physical and emotional closeness in early life is a cornerstone of optimal infant growth and development. Maternal stress and depression have been shown to have adverse neurodevelopmental effects in infants ${ }^{9}$ and may enhance the deleterious effect of newborn stress. Conversely, maternal closeness and early interaction may moderate infants' physiologic stress responses, affecting the degree to which stress exposure might impact neurodevelopment. Maternal-infant contact as provided during Kangaroo care can lessen stress responses and promote positive neurodevelopment. ${ }^{10,11}$ More parental presence and holding in the NICU have been found to be associated with better outcomes. ${ }^{12}$ Especially during this stressful time, strategies to enhance sensitive parenting and positive family processes will provide a developmentally appropriate environment. ${ }^{13}$

I started my review by stating that infant exposure to cumulative stress in the NICU is a major unsolved challenge in 
newborn care. When contemplating the NSE model, I deduced the reader might initially be inclined to think mostly about the experience of stress in the NICU and its potential adverse effects on preterm infants' development. This is, in my view, the desired starting point from which to approach the newborn's bedside: to have an awareness of the potential harm that our caregiving and procedures can cause. And yet, when I read the article again and let my background as a NIDCAP-trained and experienced neonatologist guide my reflection, I found myself thinking less about the potentially negative experience of stress, and much more engaged in envisioning the nearly boundless possibilities we have to ease and buffer that stress in the NICU.

Because stress experiences have a biological embedding, as the NSE model proposes, the infant's expectation for maternal closeness, physical contact and relationship is certainly biologically embedded as well. We know the brain of the human infant is wired for relationships and early physical contact. ${ }^{14,15}$ By capitalizing on resources readily available in every NICU (infants, parents, love, and the unspoken yearning for closeness and relationship), we can do a meaningful job in reducing and buffering the experience of stress for preterm infants. A NIDCAP-based education gives us, as clinicians, two unique tools to accomplish this important "stress-reducing" job: our skills to observe infant stress and communicate it to those who care for them, and our unequivocal understanding that parents are the infants' most consistent and reliable caregivers.

\section{References}

1. Smith GC, Gutovich J, Smyser C, Pineda R, Newnham C, Tjoeng TH, Inder T. (2011). Neonatal intensive care unit stress is associated with brain development in preterm infants. Annals of Neurology, 70(4):541-549. https://doi.org/10.1002/ana.22545
2. Vinall J, Miller SP, Bjornson, BH, Fitzpatrick KP, Poskitt KJ, Brant R, Grunau RE. (2014). Invasive procedures in preterm children: Brain and cognitive development at school age. Pediatrics, 133(3):412-421. https://doi.org/10.1542/peds.2013-1863

3. Ranger M, Chau CM, Garg A, Woodward TS, Beg MF, Bjornson B, Grunau RE. (2013). Neonatal pain-related stress predicts cortical thickness at age 7 years in children born very preterm. PLoSONE, 8(10): e76702. https://doi.org/10.371/journal.pone.0076702

4. Cong X, Wu J, Vittner D, Xu W, Hussain N, Galvin S, Henderson WA. (2017). The impact of cumulative pain/stress on neurobehavioral development of preterm infants in the NICU. Early Human Development, 108:9 -16. https://doi.org/10.1016/j.earlhumdev.2017.03.003

5. Berens AE, Jensen SKG, Nelson CA. (2017). Biological embedding of childhood adversity: from physiological mechanisms to clinical implications. BMC Med, 20;15(1):135. doi: 10.1186/s12916-017-0895-4. Review.

6. Carlo WA, McDonald SA, Tyson JE, et al. (2011). Cytokines and Neurodevelopmental Outcomes in Extremely Low Birth Weight Infants. J Pediatr. 159(6): 919-925. .e3. doi: 10.1016/j.jpeds.2011.05.042. PMID:21798559

7. Grunau RE, Cepeda IL, Chau CM, Brummelte S. Weinberg J, Lavoie PM, Turvey SE. (2013). Neonatal pain-related stress and NFKBIA genotype are associated with altered cortisol levels in preterm boys at school age. PLoS ONE, 8(9), e73926. https://doi. org/10.1371/journal. pone.0073926

8. Alberts J. (2020). A Funny Thing Happened on the Way to the Hospital. Developmental Observer, 13 (1):22. DOI: 10.14434/do. v13i1.29094.

9. Stanley C, Murray L, Stein A. (2004). The effect of postnatal depression on mother infant interaction, infant response to the Still-Face perturbation, and the performance on an Instrumental Learning task. Development and Psychopathology, 16:1-18.

10. Feldman R. (2004). Mother-infant skin-to-skin contact and the development of emotion regulation. In S. P. Shohov (Ed.), Advances in psychology research (pp. 113-131). Hauppauge, NY; Nova Science.

11. Feldman R, Eidelman AI, Sirota L, Weller A. (2002). Comparison of skin-to-skin (Kangaroo) and traditional care: parenting outcomes and preterm infant development. Pediatrics, 110, 16-26.

12. Reynolds LC, Duncan MM, Smith GC, Mathur A, Neil J, Inder T, Pineda RG. (2013). Parental presence and holding in the neonatal intensive care unit and associations with early neurobehavior. Journal of Perinatology 33:636-641.

13. Pineda R, Bender J, Hal IB, Shabosky L, Annecca A, Smith J. (2018). Parent participation in the neonatal intensive care unit: Predictors and relationships to neurobehavior and developmental outcomes. Early Hum Dev,117:32-38. doi: 10.1016/j.earlhumdev.2017. PMID: 29275070

14. Schore AN (1994). Affect Regulation and the Origins of the Self: The Neurobiology of Emotional Development: Hillsdale, NJ

15. Siegel DJ (1999). The developing mind. How relationships and the brain interact to shape who we are. 3rd Ed. The Guilford Press.
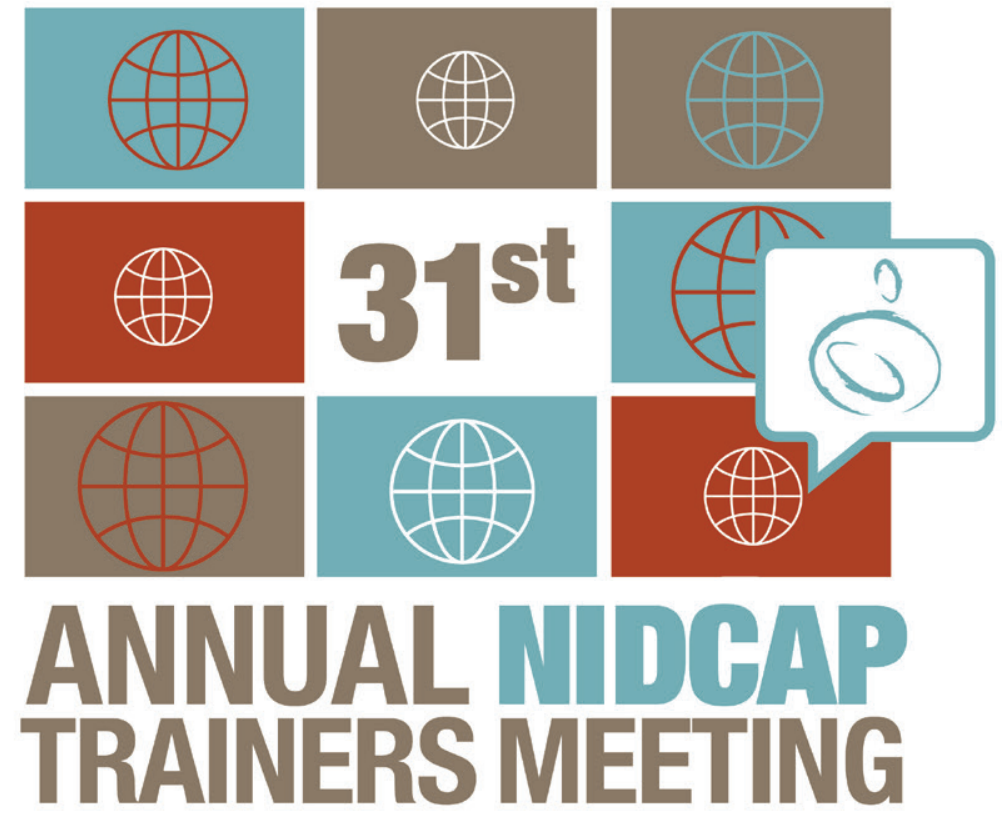

\section{Implementing NIDCAP with New Challenges, New Ways to Connect}

\author{
Hosted by the NFI \\ 21-23 October 2020 \\ 1800 - 2130 GMT
}
This will be a virtual meeting by invitation only, using an online platform. Further details will be circulated via the NFI GoogleGroup list.




\section{The following are a selection of publications from late 2019 to early 2020 relevant to NIDCAP.}

\section{9}

1. Alvarez MJ, Rodriguez-Gonzalez D, Roson M, Lapena S, Gomez-Salgado J, Fernandez-Garcia D. Effects of massage therapy and kinesitherapy to develop hospitalized preterm infant's anthropometry: A quasi-experimental study. Journal of Pediatric Nursing. 2019, 46:e86-e91. DOI: 10.1016/j.pedn.2019.03.015

The implementation of a massage therapy and kinesitherapy protocol is beneficial for the anthropometric development of hospitalized preterm infants. An easy to administer and costeffective intervention such as massage therapy and kinesitherapy can improve the anthropometric development of preterm infants and reduce growth-related morbidity in the short, medium, and long term.

2. Baghlani R, Hosseini MB, Safaiyan A, Alizadeh M, Arshadi-Bostanabad M. Neonatal intensive care unit nurses' perceptions and knowledge of newborn individualized developmental care and assessment program: A multicenter study. Iranian Journal of Nursing and Midwifery Research. 2019, 24:113-117. DOI: 10.4103/ijnmr.IJNMR_54_18

This cross-sectional study was conducted on 149 nurses working in the NICUs across Iran. Three questionnaires were used to collect demographic data and to explore the nurses' perceptions and knowledge of the NIDCAP program. The results of this study showed that the majority of nurses participating in the study had high knowledge about NIDCAP.

3. Butler S, Sadhwani A, Stopp C, Singer J, Wypij D, DunbarMasterson C, Ware J, Newburger J. Neurodevelopmental assessment of infants with congenital heart disease in the early postoperative period. Congenital Heart Disease. 2019, 14(2):236-245. DOI: $10.1111 /$ chd.12686

The neurodevelopment of a convenience sample of high-risk infants following cardiac surgery but before hospital discharge were evaluated using an adaptation of the Newborn Behavioral Observation. At discharge, postoperative infants with CHD had impairments in autonomic, motor, attention, and state regulation following cardiac surgery. Findings suggest that neurodevelopmental follow-up and intervention should begin early in infancy.
4. Chuang LJ, Wang SH, Ma MC, Lin CN, Chen C, Huang M. A modified developmental care bundle reduces pain and stress in preterm infants undergoing examinations for retinopathy of prematurity: A randomised controlled trial. Journal of Clinical Nursing. 2019, 28(3-4):545-559. PMID: 30091495, DOI: 10.1111/jocn. 14645

To determine the comparative efficacy of developmental care versus standard care for reducing pain and stress in preterm infants during examinations for retinopathy of prematurity (ROP). Since the results show the benefits of developmental care in an ROP examination, it can be the practical evidence basis by which to develop a standard of procedure or guideline for clinical practice.

5. Griffiths N, Spence K, Loughran-Fowlds, Westrup B. Individualised developmental care for babies and parents in the NICU: Evidence-based best practice guideline recommendations. Early Human Development. 2019, 139. DOI: 10.1016/j.earlhumdev.2019.104840

The application of a systematic approach to improve practice is considered the most effective strategy for implementing neuroprotective developmentally supportive care. The content of this paper incorporates evidence-based systematic reviews to guide clinicians in the application of developmentally supportive interventions.

6. Mirlashari J, Valizadeh S, Navab E, Craig J, Ghorbani F. Dark and bright-two sides of family-centered care in the NICU: A qualitative study. Clinical Nursing Research. 2019, 28:869-885. DOI: 10.1177/1054773818758171

The aim of the study was to explore the lived experiences of NICU nurses on implementing FCC. This study provided deeper understanding about nurses' perceptions of FCC implementation. In Muslim developing countries, FCC implementation is challenging and nurses are under extra pressure because of a shortage in nursing workforce; however, having positive experiences with family participation and valuing their beliefs allowed them to support family involvement.

7. Painter L, Lewis S, Hamilton B. Improving neurodevelopmental outcomes in NICU patients. Advances in Neonatal Care. 2019, 19(3):236-243. DOI: 10.1097/ ANC.0000000000000583 
The purpose of this study was to measure the effectiveness of a developmental positioning intervention on length of stay, weight gain, and tone/flexion compared with neonates without structured positioning. With greater structure and consistent attention to developmental positioning, outcomes are positively affected. Further research with larger sample sizes will identify stronger associations and relationships between positioning and outcome measures.

8. Park J, Kim JS. Factors influencing developmental care practice among neonatal intensive care unit nurses. Journal of Pediatric Nursing. 2019, 47:e10-e15. DOI: 10.1016/j. pedn.2019.03.014

This study found that professional efficacy had the largest influence on developmental care practice, followed by perception of developmental care, and a task-oriented organizational culture. Clinical and educational experience regarding developmental care and working environment was not associated with developmental care practice. A practical training program should be provided to nurses to promote confidence in implementing developmental care for preterm infants.

9. Shanty L, Dowling R. Sonnenschein S, Hussey-Gardner B. Evaluation of an early language and literacy program for parents of infants in the NICU. Neonatal Network. 2019, 38(4):206-216. DOI: 10.1891/0730-0832.38.4.206

To evaluate the effect of a NICU parent education program on parents' early language and literacy practices, and on their confidence interpreting and responding to infant signals. The program significantly increased intention to engage in more early language and literacy practices, and increased parent-reported knowledge of how and when to interact with their infants. The majority of interviewed parents reported engaging in these practices one to two weeks later.

10. Treyvaud K, Spittle A, Anderson PJ, O'Brien K. A multilayered approach is needed in the NICU to support parents after the preterm birth of their infant. Early Human Development. 2019, 139. DOI: 10.1016/j. earlhumdev.2019.104838

A multilayered approach to supporting parents of infants born preterm in the NICU is recommended, with evidence specifically for including layers of individual psychological and psychosocial support, peer-to-peer support, and family centered care. Consideration of fathers in the NICU, and areas for future research are also discussed.

\section{0}

11. Almadhoob A, Ohlsson A. Sound reduction management in the neonatal intensive care unit for preterm or very low birth weight infants. EBM Reviews - Cochrane Database of Systematic Reviews Cochrane Database of Systematic Reviews. 2020. Issue 1. Art. No.: CD010333. DOI: 10.1002/14651858.CD010333.pub3

To date, 34 infants have been enrolled in a randomized controlled trial (RCT) testing the effectiveness of reducing sound levels that reach the infants' ears in the NICU. Based on the small sample size of this single trial, no recommendations were made for clinical practice. Larger, well designed, conducted and reported trials are needed.

12. Anderson PJ, Treyvaud K, Spittle AJ. Early developmental interventions for infants born very preterm - what works? Seminars in Fetal and neonatal Medicine. 2020, online May 15 DOI:10.1016/j.siny.2020.101119

Although early developmental interventions vary widely in focus, timing, and mode of delivery, evidence generally supports the effectiveness of these programs to improve specific outcomes for children born very preterm and their families. However, little is known about mechanisms for effectiveness, cost- and long-term effectiveness, which programs might work better for whom, and how to provide early intervention services equitably. This information is critical to facilitate systematic integration of effective developmental interventions into clinical care for infants born very preterm and their families.

13. Bembich S, Trappan A, Galimberti A,Taglieri J, Scolz S, Risso FM, Sanson G. The role of weighing-bathing sequence and postmenstrual age in eliciting adaptive/ maladaptive responses in very low birth weight preterm infants. Journal for Specialists of PediatricNursing.

2020;e12292.DOI: 10.1111/jspn.12292

Responses were assessed using an observational sheet based on Als' Synactive Theory of Development. Autonomic and motor responses were scored according to five-point Likert scales. Effects of weighing/bathing execution sequence and post menstrual age (PMA) on autonomic and motor response scores were analyzed by linear multiple regression analysis. The real-time recognition of adaptive/maladaptive responses allows nurses to personalize their approach to preterm infants, taking into account PMA and adjusting the appropriate sequence of execution of weighing/bathing nursing procedures.

14. Buil A, Sankey C, Laurence C, Apter G, Gratier M, Devouche E. Fostering mother-very preterm infant communication during skin-to-skin contact through a modified positioning. Early Human Development. 2020, 141. DOI: $10.1016 /$ j.earlhumdev.2019.104939

The study shows that Supported Diagonal Flexion (SDF) positioning creates more opportunities for mother-infant communication during SSC. SDF positioning fosters a greater multimodal

$22 \cdot 2020 \cdot$ Developmental Observer 
temporal proximity, thus supporting a more qualitative motherinfant communication.

15. Govindaswamy P, Laing SM, Waters D, Walker K, Spence $\mathrm{K}$, Badawi N. Fathers' needs in a surgical neonatal intensive care unit: Assuring the other parent. Plos One. 2020, 15(5):e0232190. DOI: 10.1371/journal.pone.0232190

Reassurance is a priority for fathers of neonates in a surgical NICU, particularly regarding infant pain management and comfort. It is important that health-care professionals provide reliable, honest information and open-access visiting. Notably, fathers seek greater recognition of their role in the NICU, beyond being the 'other' parent.

16. Griffiths N, James-Nunez K, Spence K, Crowle C, Pettigrew J, Loughran-Fowlds A. The evolution of an interdisciplinary developmental round in a surgical neonatal intensive care unit. Advances in Neonatal Care. 2020, May 06, Volume Publish Ahead of Print. DOI: 10.1097/ ANC.0000000000000741

This article provides retrospective audit data of a developmental round intervention in the surgical neonatal intensive care unit with a focus on data over four years to highlight key areas, including the structure and process, recommended educational standards for team members, and parental engagement, as key markers for developmental round efficacy. Future research should focus on the link between the developmental round intervention and long-term neonatal outcomes.

17. Jannes C, Miedaner F, Langhammer K, Enke C, Göpel W, Kribs A, Nitzsche A, Riedel R, Woopen C, Kuntz L, Roth B. Increased parental satisfaction by unrestricted visiting hours and developmentally supportive care in NICUs - results of a German multicenter study. The Journal of MaternalFetal \& Neonatal Medicine. 2020, 33(11): 1874-80. DOI: 10.1080/14767058.2018.1532499

Very low birthweight infants from 66 NICUs in Germany were enrolled in this multicenter study. 1493 questionnaires were completed by 1277 parents. The existence of unrestricted visiting hours and standardized procedures for developmentally supportive care were positively associated with parental satisfaction. Fostering the parent-infant interaction through the provision of developmentally supportive care and unrestricted visiting hours for parents whose infants are hospitalized within an NICU significantly contributes to the satisfaction of parents.

18. Johnson MR, Helm JM. Neonatal and early infant development. North Carolina Medical Journal. 2020, 81(1):46-47. DOI: $10.18043 / \mathrm{ncm} .81 .1 .46$
As with neonatal development, the field of infant mental health continues to evolve. Another current trend is the development of evidence-based models of both prevention and therapeutic intervention for infants and very young children, including direct parent support and interventions to strengthen the parent-child relationship. The field of infant and young child mental health has also embraced the importance of collaboration with other professionals and service systems.

19. Miller TA, Lisanti AJ, Witte MK, Elhoff JJ, Mahle WT, Uzark KC, Alexander N, Butler SC. A collaborative learning assessment of developmental care practices for infants in the cardiac intensive care unit. Journal of Pediatrics. 2020. DOI: 10.1016/j.jpeds.2020.01.043

A collaborative learning approach was used to stratify, assess, and compare individualized developmental care practices among multidisciplinary teams at six pediatric heart centers. The collaborative findings were a first step toward strategies to quantify and measure developmental care practices in the cardiac intensive care unit to assess the association of complex inpatient practices with long-term neurodevelopmental outcomes.

20. Mirlashari J, Brown H, Fomani F, Khoshnavay de Salaberry J, Tahereh K, Khoshkhou F. The challenges of implementing family-centered care in NICU from the perspectives of physicians and nurses. Journal of Pediatric Nursing. 2020, 50:e91-e98. DOI: 10.1016/j. pedn.2019.06.0

The implementation of family-centered care (FCC) in the neonatal intensive care unit in Iran is shaped by the health care provider, cultural, legal and operational challenges. Organizational, managerial and operational changes are required for FCC implementation. Nurses and physicians are well-positioned as leaders and facilitators of family-centered care implementation within the neonatal intensive care unit.

21. Morag I, Ohlsson A. Cycled light in the intensive care unit for preterm and low birth weight infants. EBM Reviews - Cochrane Database of Systematic Reviews Cochrane Database of Systematic Reviews. 1, 2020. DOI: 10.1002/14651858.CD006982.pub2

One additional study enrolling 38 participants was included in this update, for a total of nine studies reporting on 544 infants. Results from one additional study strengthen our findings that cycled lighting (CL) versus continuous bright light shortens length of stay, as does CL versus near darkness (ND). The quality of the evidence on both comparisons for this outcome according to GRADE was low. Future research should focus on comparing CL versus ND. 
22. Pierrat, V, Marchand-Martin L, Durrmeyer X. Vasante L, Burguet A, Cambonie G, Kuhn P, Datin-Dorrière V, Durox M, Kaminski M, Carbajal R, Ancel P-Y. Neurodevelopmental Care Study Group of EPIPAGE -2. Perceived maternal information on premature infant's pain during hospitalization: the French EPIPAGE-2 national cohort study. Pediatric Research. 2020, 87:153162. DOI: $10.1038 / s 41390-019-0422-8$

Analyses of questionnaires from the French national cohort study of preterm neonates, EPIPAGE-2. Perceived Maternal Information on Infants' Pain (PMIP) was derived from mothers' answers to questions about information perceived on both pain assessment and management. Mothers reporting PMIP as "sufficient" were more frequently present and more likely comforting their child during painful procedures. Factors independently associated with "sufficient" PMIP were high maternal education, gestational age $<29$ weeks, daily maternal visits, perception of high team support, and implementation of the newborn individualized developmental care and assessment program.

\section{Pineda R, Wallendorf M, Smith, J. A pilot study} demonstrating the impact of the supporting and enhancing NICU sensory experiences (SENSE) program on the mother and infant. Early Human Development. 2020, 144, DOI: 10.1016/j.earlhumdev.2020.105000

To explore differences in maternal mental health and infant neurobehavioral outcome among infants who received and did not receive the Supporting and Enhancing NICU Sensory Experiences (SENSE) program. Preliminary evidence demonstrates improvements in maternal confidence and infant neurobehavioral performance following SENSE implementation.

24. Soleimani F, Azari N, Ghiasvand H, Shahrokhi A, Rahmani N, Fatollahierad S. Do NICU developmental care improve cognitive and motor outcomes for preterm infants? A systematic review and meta-analysis. $B M C$ Pediatrics. 2020, 20, 67. DOI: 10.1186/s12887-020-1953-1

Current evidence suggests that developmental care in NICU settings could have significant effects on mental and motor development of preterm infants, especially at 12 months of age. However, because of clinical heterogeneity, more studies are needed to evaluate the effects of developmental NICU care in the development of preterm infants.
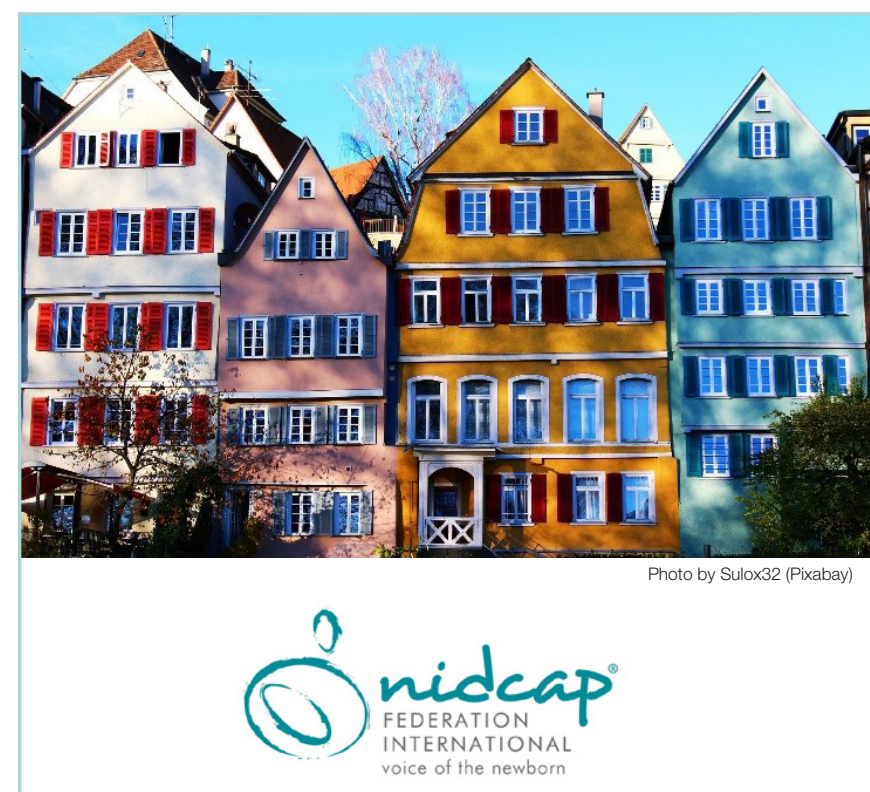

\section{$32^{\text {nd }}$ ANNUAL NIDCAP}

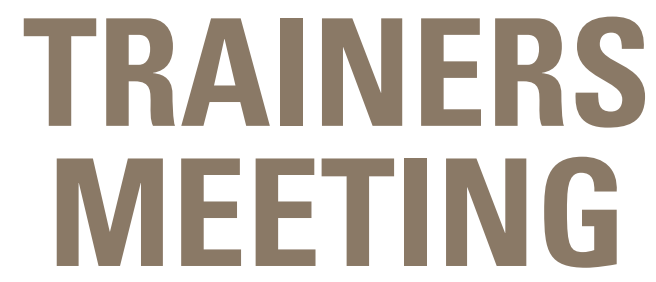

September 24-26th, 2021

\author{
Seminaris Hotel Bad Boll \\ 73087 Bad Boll, Germany \\ (30 km from Stuttgart)
}
Hosted by the NIDCAP Training Center in Tübingen, Germany
(By Invitation Only)

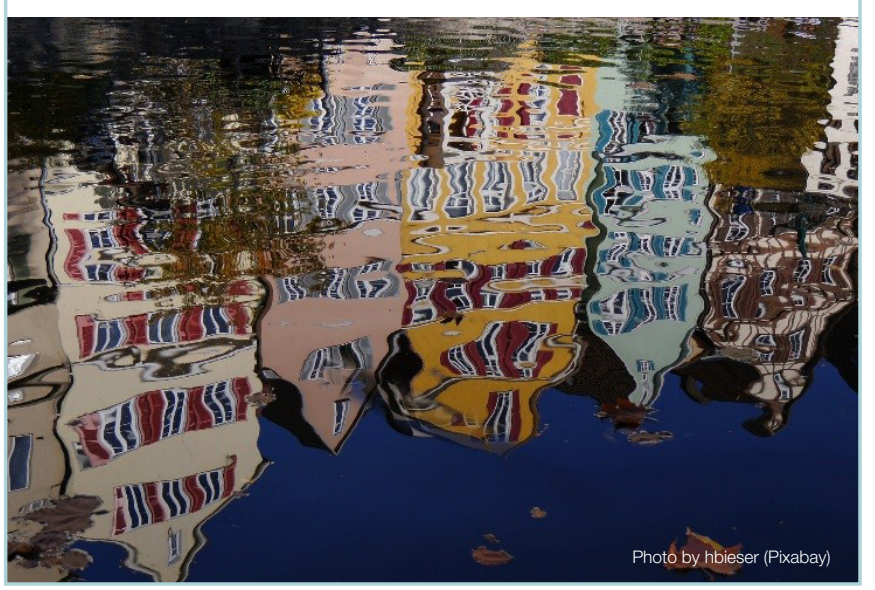


Julia Giesen, NIDCAP Professional-in-Training,

Edmonton, Canada

$\mathrm{H}$ ello from the Edmonton NIDCAP Training Centre

Canada, ENTCC for short! I am Julia Giesen and I had the pleasure to meet many of you in the world-spanning NIDCAP community at the NIDCAP Trainers Meeting in our fair city in 2017. That meeting inspired me to pursue NIDCAP training which I started the following spring under the direction of our trainer Juzer Tyebkhan. Initially I found the observations overwhelming. Each observation opened my eyes to something I had never seen before, much of it hard to stomach. Could our little patients really be having such a difficult time, so often, without us being aware? What must that feel like? And what does that do to them over time? I struggled to get down in words what I was seeing, to describe it accurately and in a way that families would easily understand. I spent hours picking out the words for my reports and the days were long. At the end of the day after hours at the keyboard the last thing I wanted to do was to fill out another form for the Journal Page. I couldn't think straight anymore and it felt too raw to reflect on it right away. I took the evening to let things settle in, poured myself a cup of tea, grabbed pen and paper, and wrote. I tried a number of reflection styles but what resonated most for me was to write

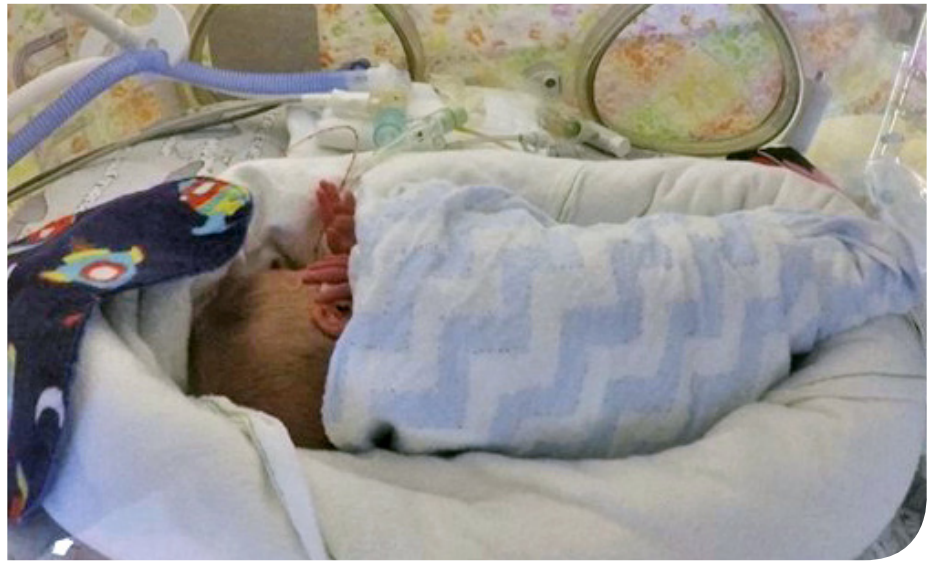

freely and what ensued were a series of poems. I am sharing some of my poems with you, hoping they help you see what I saw on this great NIDCAP journey.

This first poem is from an observation in January 2019 on a little boy named Alex. Alex was born at 25 weeks and was six days old. He showed me that the protective effect of the womb may indeed last for several days after birth before beginning to fade as we encounter life on our own.

\section{“On Our Watch"}

Today you showed me something new Could it possibly be true?

That when you were born you started out whole All systems working as is our goal

To have you move between your states With smooth transitions and no mistakes

No interruptions to get you there And nothing breaking the moment where You grow and heal and find good rest Where your little brain can do its best
And here we stand at a fork in the road An opportunity to lay down the code

For how you will do in the years ahead Will we be with you or will you lay in your bed Cycling through trying to breathe on your own Your little struggles not being known Will you continue to be so strong? Or will we pick the road that is long?

On our watch 


\section{Developmental}

\section{Observer}

The Official Newsletter of the NIDCAP ${ }^{\circledR}$

Federation International

Developmental Observer current and past issues from: https://scholarworks.iu.edu/journals/

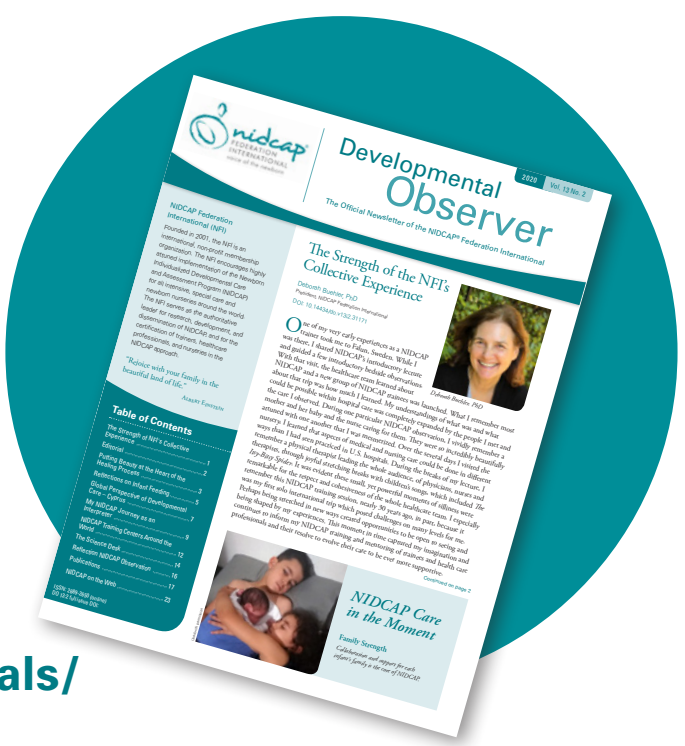

ISSN: 2689-2650 (online)

All published items have a unique document identifier (DOI)

DOI: $10.14434 /$ do.v13i2.31223

NIDCAP Federation International Board of Directors and Staff 2019-2020

President

Deborah Buehler, PhD

NIDCAP Master Trainer

APIB Trainer

Director, West Coast NIDCAP and APIB Training Center

email: nfipresident@nidcap.org

Vice President

Dorothy Vittner, RN, PhD

Senior NIDCAP Trainer

email:dvitt8@gmail.com

Treasurer

Gloria McAnulty, PhD

National NIDCAP Training Center

email: gloria.mcanulty@childrens.harvard.edu

\section{Secretary}

Jean Powlesland, RN, MS

NIDCAP Trainer

Director, Children's Hospital of University of

Illinois NIDCAP Training Center

email: jpowles/@uic.edu

\section{Fatima Clemente, MD}

NIDCAP Trainer

Co-Director, São João NIDCAP Training Center

email: clemente.fatima@gmail.com
Mandy Daly, Dip. H Diet and Nutrition, ACII, DLDU

Family Representative, Dublin, Ireland

email: mandy.daly@yahoo.co.uk

Jennifer Degl, MS

Family Representative, New York, USA email: jenniferdegl@gmail.com

Maria Lopez Maestro, MD, PhD NIDCAP Trainer

Hospital Universitario 12 de Octubre NIDCAP Training Center

email: mariamaestro@gmail.com

Dalia Silberstein, RN, PhD

NIDCAP Trainer

Co-Director, Israel NIDCAP Training Center email: dalia.silberstein@clalit.org.il

\section{Juzer Tyebkhan, MB}

NIDCAP Trainer

Director, Edmonton NIDCAP Training Centre

email: juzer.tyebkhan@albertahealthservices.ca
STAFF

Rodd E. Hedlund, MEd

Director, NIDCAP Nursery Program NIDCAP Trainer

email: nidcapnurserydirector@nidcap.org

Sandra Kosta, BA

Executive Director of Administration and Finance

email: sandra.kosta@childrens.harvard.edu

Founder of the NIDCAP Federation INTERNATIONAL, INC.

\section{Heidelise Als, PhD}

NIDCAP Founder, Past President 2001-2012 Senior NIDCAP Master Trainer APIB Master Trainer

Director, National NIDCAP Training Center email: heidelise.als@childrens.harvard.edu 


\section{NIDCAP on the Web}

\section{NIDCAP Training Centers - Facebook Pages}

Many of the Training Centers and NIDCAP groups have established their own Facebook pages. These pages provide useful resources for members and by joining the groups and sharing the pages you are helping to spread information about NIDCAP. Here are a few to get you started. If you know of others please send an email to developmentalobserver@nidcap.org for inclusion in the next issue.

During the challenging times of the past six months, our NFI community has shown resilience in getting the message across for hospitalized newborns and their families. Here is a snapshot of some of the important topics and celebrations supported by the various NIDCAP Training Centers.
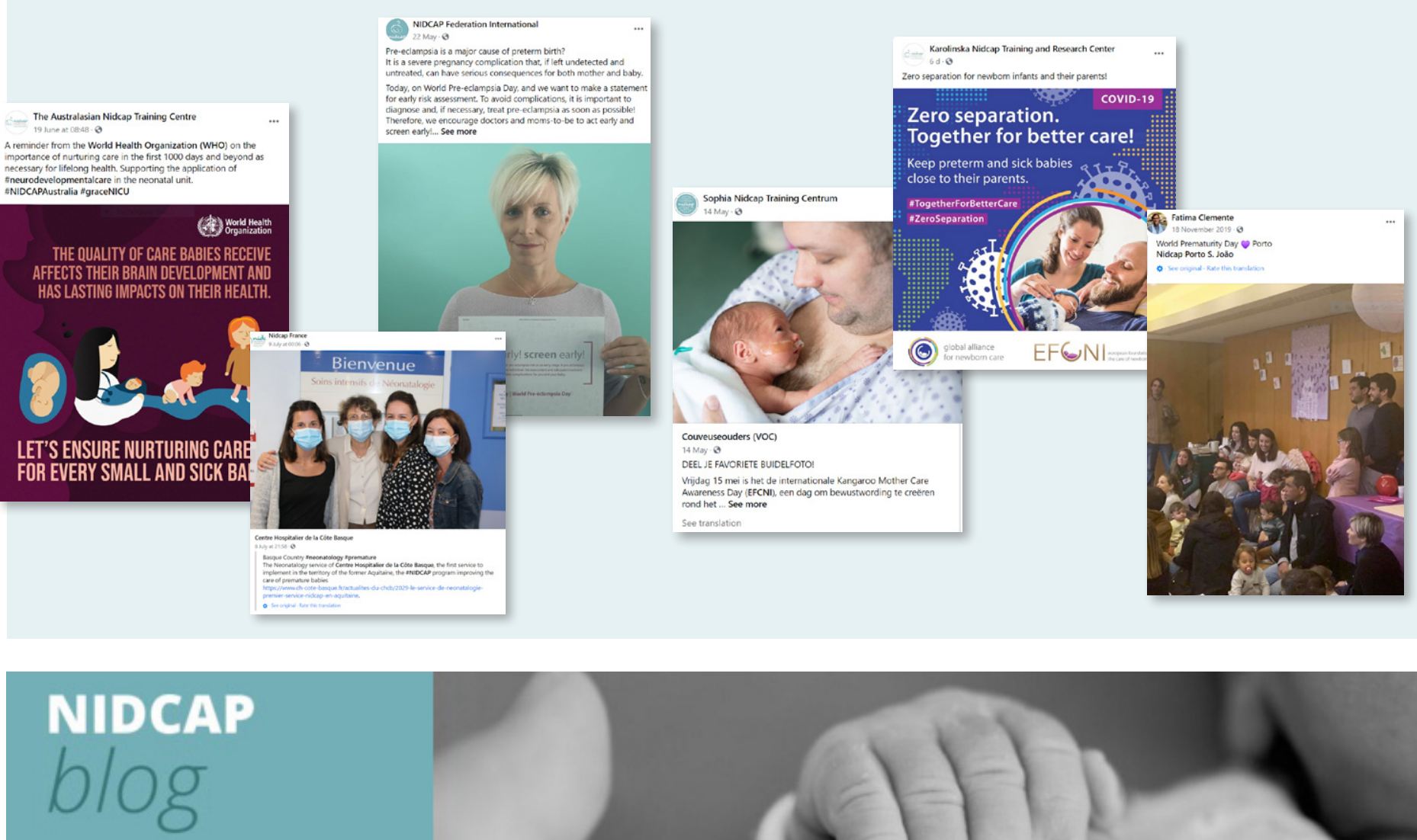

\section{The Official Blog of NIDCAP Federation International}

The NFI's NIDCAP Blog offers observations from many different perspectives on NIDCAP and its implementation, such as NIDCAP and APIB training, Nursery Certification, the science behind the approach, the family experience with NIDCAP, the NFI, and much more. We encourage you to visit the NIDCAP Blog and to leave comments for our bloggers and our NIDCAP community in general. If interested in becoming a guest blogger please contact Sandra Kosta at sandra.kosta@nidcap.org.

\section{Follow us on all of our social media platforms:}

Like Us on Facebook

Follow us on Twitter
Follow our posts on Instagram

Connect with colleagues

on Linkedln
Watch our videos on You Tube

Read and participate on our NIDCAP Blog 


\section{AMERICAS}

\section{North America}

* CANADA

Edmonton NIDCAP Training Centre

Stollery Children's Hospital

Royal Alexandra Site

Edmonton, $A B$, Canada

Co-Directors: Andrea Nykipilo, RN and

Juzer Tyebkhan, MB

Contact: Juzer Tyebkhan, MB

email: Juzer.Tyebkhan@ahs.ca

\section{UNITED STATES}

St. Joseph's Hospital NIDCAP Training Center St. Joseph's Hospital and Medical Center Phoenix, Arizona, USA

Co-Directors: Bonni Moyer, MSPT and

Marla Wood, RN, BSN, MEd

Contact: Windy Crow

email:windy.crow@dignityhealth.org

West Coast NIDCAP and APIB Training Center University of California San Francisco San

Francisco, California, USA

Director and Contact: Deborah Buehler, PhD

email:dmb@dmbuehler.com

Children's Hospital of University of Illinois (CHUI) NIDCAP Training Center

University of Illinois Medical Center at Chicago

Chicago, Illinois, USA

Co-Directors: Doreen Norris-Stojak MS, BSN, RN

NEA-BC \& Jean Powlesland, RN, MS

Contact: Jean Powlesland, RN, MS

email: jpowles/@uic.edu

National NIDCAP Training Center

Boston Children's Hospital and

Brigham and Women's Hospital

Boston, Massachusetts, USA

Director: Heidelise Als, PhD

Contact: Sandra M. Kosta, BA

email: nidcap@childrens.harvard.edu

\section{Carolina NIDCAP Training Center}

WakeMed, Division of Neonatology Raleigh,

North Carolina, USA

Director and Contact: James Helm, PhD

email: jimhelm27@gmail.com

NIDCAP Cincinnati

Cincinnati Children's Hospital Medical Center Cincinnati, Ohio, USA

Director: Michelle Shinkle, MSN, RN

Contact: Linda Lacina, MSN

email: Linda.Lacina@cchmc.org

\section{South America}

\section{ARGENTINA}

Centro Latinoamericano NIDCAP \& APIB

Fernández Hospital

Fundación Dr. Miguel Margulies and

Fundación Alumbrar, Buenos Aires, Argentina

Director and Contact: Graciela Basso, MD, PhD

email: basso.grace@gmail.com
OCEANIA

AU.? AUSTRALIA

Australasian NIDCAP Training Centre

The Sydney Children's Hospitals Network Westmead, Australia

Co-Directors: Alison Loughran-Fowlds MBBS,

DCH, FRACP, PhD and Kaye Spence AM, MN

Contact: Nadine Griffiths, NIDCAP trainer

email: SCHN-NIDCAPAustralia@health.nsw.gov.au

\section{EUROPE}

\section{BELGIUM}

The Brussels NIDCAP Training Center

Saint-Pierre University Hospital Free University of

Brussels Brussels, Belgium

Director: Inge Van Herreweghe, MD

Co-Director: Marie Tackoen, MD

Contact: Delphine Druart, RN

email: delphine_druart@stpierre-bru.be

\section{DENMARK}

Danish NIDCAP Training and Development Center Aarhus University Hospital, Aarhus N, Denmark

Director: Tine Brink Henriksen Professor,

Consultalt, PhD

Co-Director: Majken Grund Nielsen, RN

Contact: Eva Jörgensen, RN

email: auh.nidcaptrainingscenter@rm.dk

FRANCE

French NIDCAP Center, Brest

Medical School, Université de Bretagne

Occidentale and University Hospital

Brest, France

Director: Jean-Michel Roué, MD, PhD

Contact: Sylvie Minguy

email:sylvie.bleunven@chu-brest.fr

French NIDCAP Center, Toulouse

Hôpital des Enfant Toulouse, France

Director: Charlotte Casper, MD, PhD

Co-Director and Contact: Sandra Lescure, MD

email: lescure.s@chu-toulouse.fr

GERMANY

NIDCAP Germany, Training Center Tübingen

Universitätsklinik für Kinder- und Jugendmedizin

Tübingen, Germany

Director: Christian Poets, MD, PhD

Contact: Natalie Wetzel, RN

email: natalie.broghammer@med.uni-tuebingen.de

\section{ITALY}

Italian Modena NIDCAP Training Center

Modena University Hospital, Modena, Italy

Director: Fabrizio Ferrari, MD

Contact: Natascia Bertoncelli, PT

email: natafili@yahoo.com

Rimini NIDCAP Training Center

AUSL Romagna, Infermi Hospital

Rimini, Italy

Director and Contact: Gina Ancora, MD

Co-Director: Natascia Simeone, RN

email: gina.ancora@aus/romagna.it
- THE NETHERLANDS

Sophia NIDCAP and APIB Training Center

Erasmus MC-Sophia Children's Hospital

Rotterdam, The Netherlands

Director: Nikk Conneman, MD

Co-Director and Contact: Monique Oude Reimer, RN email: nidcap@erasmusmc.nl

NORWAY

NIDCAP Norway, Ålesund Training Center

Ålesund Hospital, Ålesund, Norway

Director: Lutz Nietsch, MD

Contact: Unni Tomren, RN

email:nidcap@helse-mr.no

PORTUGAL

São João NIDCAP Training Center

Pediatric Hospital at São João Hospital

Porto, Portugal

Director: Hercília Guimarães, MD, PhD

Co-Director and Contact: Fátima Clemente, MD

email: saojoaonidcap@chsj.min-saude.pt

\section{SPAIN}

Barcelona NIDCAP Training Center: Vall d'Hebron and Dr Josep Trueta Hospitals Hospital Universitari Vall d'Hebron, Barcelona, Spain Director and Contact: Josep Perapoch, MD, PhD email: jperapoch.girona.ics@gencat.cat

Hospital Universitario 12 de Octubre NIDCAP Training Center

Hospital Universitario 12 de Octubre, Madrid, Spain

Director: Carmen Martinez de Pancorbo, MD

Contact: María López Maestro, MD

email: nidcap.hdoc@salud.madrid.org

\section{SWEDEN}

Karolinska NIDCAP Training and Research Center Astrid Lindgren Children's Hospital at Karolinska

University Hospital Stockholm, Sweden

Director: Stina Klemming, MD

Co-Director: Björn Westrup, MD, PhD

Contact: Ann-Sofie Ingman, RN, BSN

email: nidcap@karolinska.se

\section{UNITED KINGDOM}

UK NIDCAP Centre

Department of Neonatology,

University College Hospital, London, UK

Director: Neil Marlow, DM FMedSci

Contact: Gillian Kennedy, OBE, MSc

email: gillian.kennedy4@nhs.net

\section{MIDDLE EAST}

ISRAEL

Israel NIDCAP Training Center

Meir Medical Center

Kfar Saba, Israel

Co-Directors: Ita Litmanovitz, MD and Dalia

Silberstein, RN, PhD

Contact: Dalia Silberstein, RN, PhD

email: dalia.silberstein@clalit.org.il

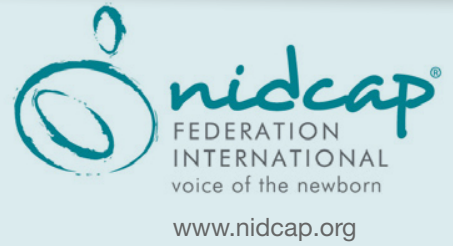

\section{Become a Member of the NFI}

The NFI has expanded opportunities for membership. Please join us! For more information and the online application form, visit our website at: www.nidcap.org or email us at nfimembership@nidcap.org 